GUILHEME BUZON GREGORES

\title{
Topografia vértebro-medular e Anestesia espinhal em Quati (Nasua nasua)
}

São Paulo

2006 
GUILHEME BUZON GREGORES

\section{Topografia vértebro-medular e anestesia espinhal em quati (Nasua nasua)}

Dissertação apresentada ao Programa de PósGraduação em Anatomia dos Animais Domésticos e Silvestres da Faculdade de Medicina Veterinária e Zootecnia da Universidade de São Paulo para a obtenção do título de Mestre em Ciências

Departamento:

Cirurgia

Área de concentração:

Anatomia dos Animais Domésticos e Silvestres

Orientador:

Profa. Dra. Silvia Renata Gaido Cortopassi

São Paulo 2006 
Autorizo a reprodução parcial ou total dessa obra, para fins acadêmicos, desde que citada a fonte.

DADOS INTERNACIONAIS DE CATALOGAÇÃO-NA-PUBLICAÇÃO

(Biblioteca da Faculdade de Medicina Veterinária e Zootecnia da Universidade de São Paulo)

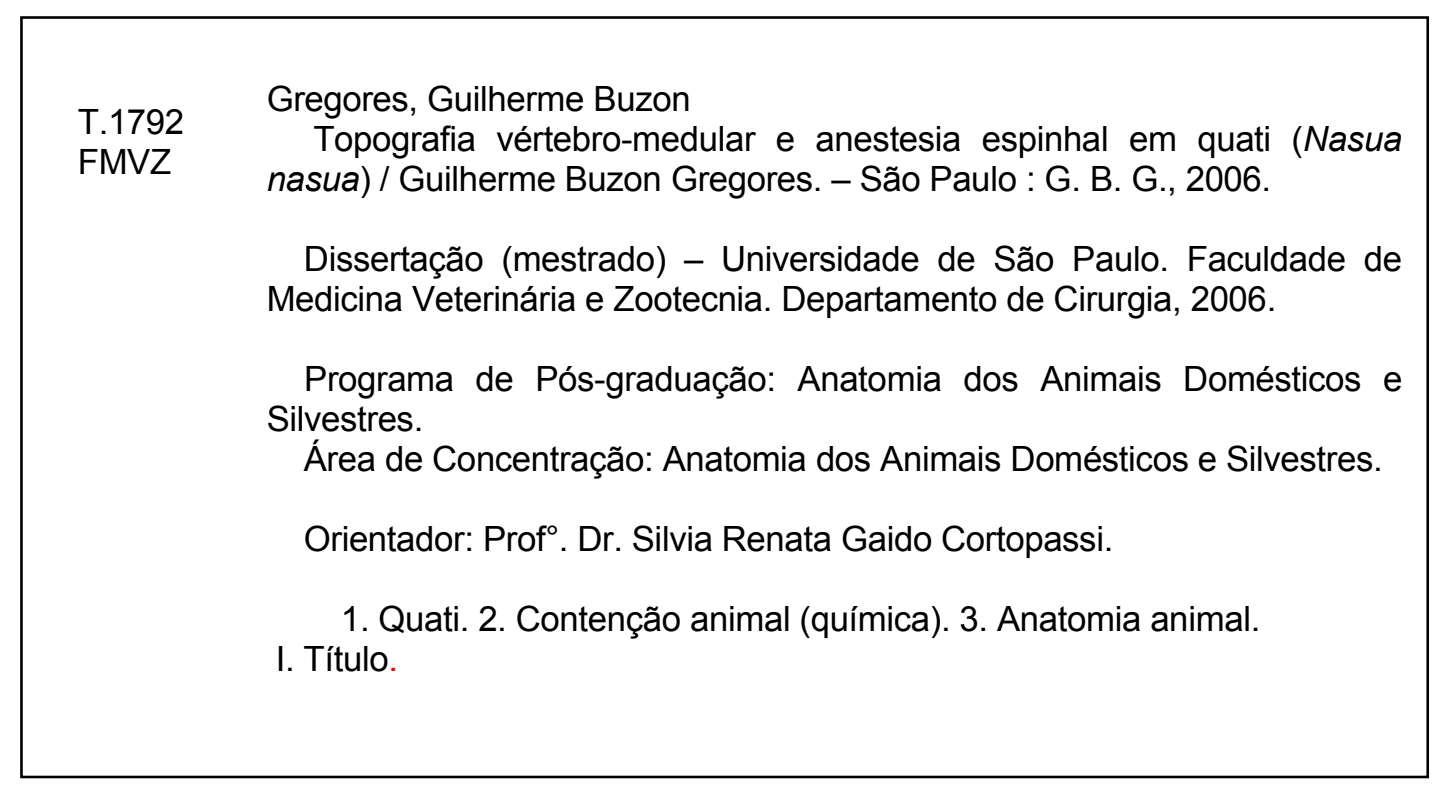




\section{FOLHA DE AVALIAÇÃO}

Nome: Gregores, Guilherme Buzon

Título: Topografia vértebro-medular e anestesia espinhal em quati (Nasua nasua)

Dissertação apresentada ao Programa de PósGraduação em Anatomia dos Animais Domésticos e Silvestres da Faculdade de Medicina Veterinária e Zootecnia da Universidade de São Paulo para a obtenção do título de Mestre em Ciências

Data:

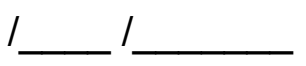

BANCA EXAMINADORA

Prof. Dr. Instituição:

Assinatura: Julgamento:

Prof.(a) Dr. (a) Instituição:

Assinatura: Julgamento:

Prof.(a) Dr. (a) Instituição: Julgamento: 


\section{UNIVERSIDADE DE SÃO PAULO \\ Faculdade de Medicina Veterinária e Zootecnia \\ Comissão Bioética}

\section{CERTIFICADO}

Certificamos que o Projeto intitulado "Topografia vértebro-medular e anestesia espinhal em quati (Nasua nasua)", protocolado sob o n954/2006, utilizando 17 (dezessete) quatis (05 cadáveres e 12 animais vivos), sob a responsabilidade da Profa. Dra. Silvia Renata Gaido Cortopassi, está de acordo com os princípios éticos de experimentação animal da Comissão de Bioética da Faculdade de Medicina Veterinária e Zootecnia da Universidade de São Paulo e foi aprovado em reunião de 16/08/06".

(We certify that the Research "Vertebro-medular topography and spinal anesthesia in coati (Nasua of nasua)", protocol number 954/2006, utilizing 17 (seventeen) coatis, under the responsibility of Profa. Dra. Silvia Renata Gaido Cortopassi, agree with Ethical Principles in Animal Research adopted by Bioethic Commission of the Faculty of Veterinary Medicine and Zootechny of University of São Paulo and was approved in the meeting of the day 08/16/2006).

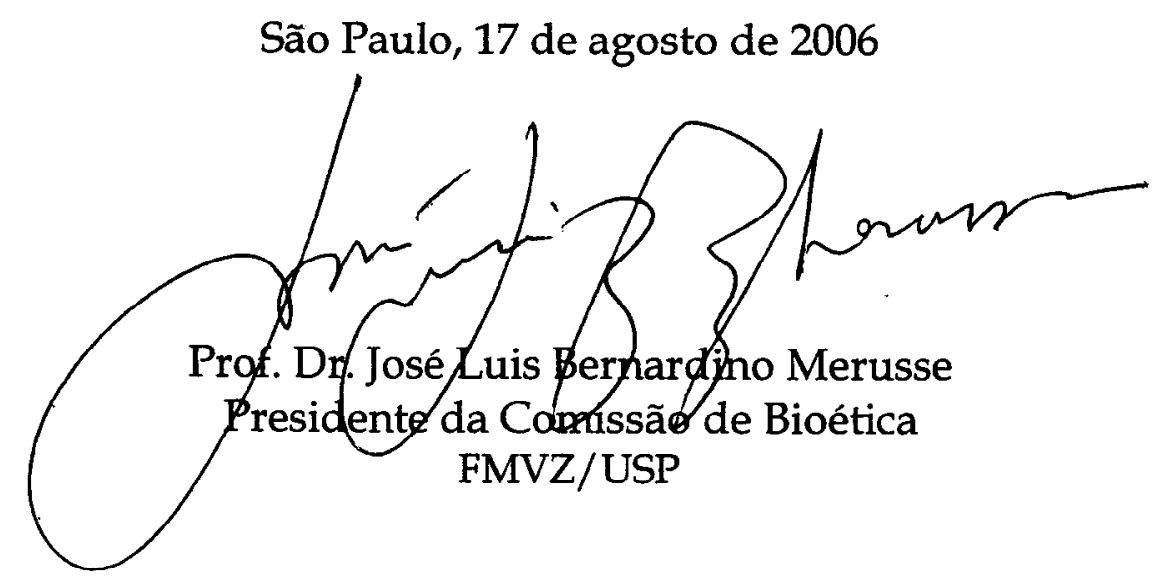

Av. Prof. Dr. Orlando Marques de Paiva, $\mathrm{n}^{\circ} 87$ - 05508-270 - Cidade Universitária "Armando de Salles Oliveira". Fax: (11) 3032-2224 - fones: (11) 309107676/7671 - e-mail: fmvz@edu.usp.br 


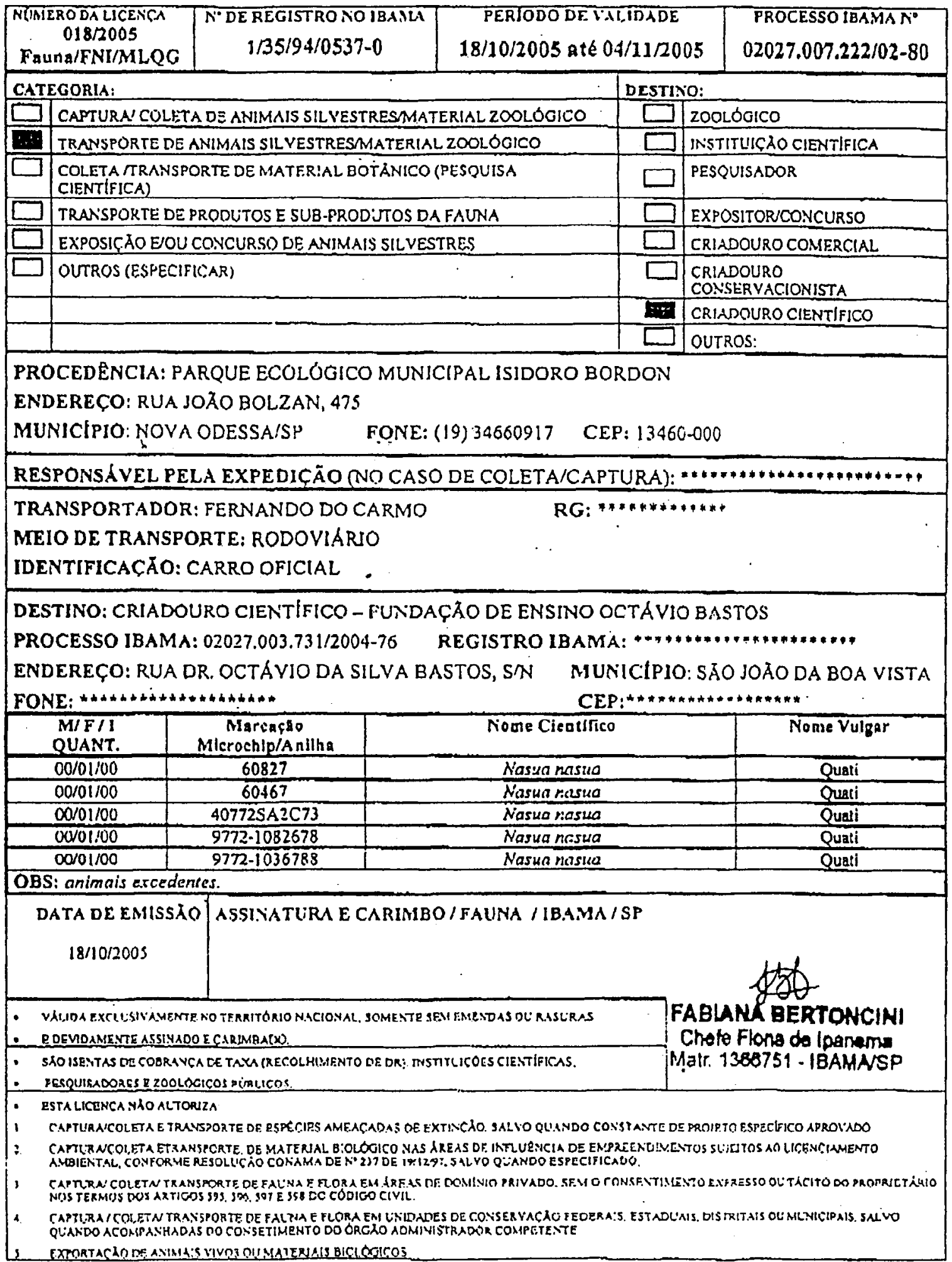

1. VA - INTERESSADO 2" VIA - IQAMA IARQUIVO 3' VIA - IBAMA IPROCESSO 14 : VIA - IBASIA / PROCESSO 2 


\section{DEDICATÓRIA}

A Deus por sempre me acompanhar nesta minha trajetória de muitas vitórias e derrotas, me dando força e iluminando meu caminho.

Aos meus pais, que permitiram minha vinda a São Paulo me dando condições para que eu conquistasse mais este passo, apenas um dos inúmeros que ainda estão por vir. Obrigado Mãe (Rosangela), Pai (Orlando) por acreditarem no meu potencial e não de hoje acreditando em todo o meu trabalho e dedicação. Dedico-lhes este trabalho como forma de gratidão por vocês existirem em minha vida.

As minhas duas irmãs Ana Laura e Maria Gabriela, por me darem força para este desafio, ajudando, auxiliando em conhecimentos e ensinamentos e ao meu cunhado Ricardo, e não poderia esquecer do meu sobrinho querido Gabriel, por ter chegado a nossa família neste momento.

A minha namorada Leandra, que acompanhou minha trajetória nesta jornada, $e$ neste momento fazendo parte da minha vida.

A minha Profa. Dra. Orientadora, Silvia Renata Gaido Cortopassi. É com grande prazer e caráter que tenho um pouco de palavras para ser adicionadas ao currículo da "Minha" orientadora. Pois tive a oportunidade de conhece-lá há cinco anos atrás, quando vim realizar um estágio obrigatório na anestesiologia, onde então já era Professora da disciplina. Recebendo-me de portas abertas, deixando-me bem àvontade, levando até a sua sala emprestando um livro para a minha tese de conclusão de curso. Desde então já muito atenciosa e prestativa. Ao passar os anos, e tendo a oportunidade de receber este privilégio, podendo ser orientado em 
um Mestado, para mim, foi uma enorme satisfação, pois devemos acreditar em sonhos, eles existem; têm muitos ainda, mas um deles já está realizado. Faltam palavras que posso expressar a minha Orientadora, por acreditar em mim neste desafio e é com todo o carinho e respeito que dedico a você este meu trabalho.

Esses bichos são já antigos como xerimbabos, "fazem tanta festa e brincam como uns gatinhos ou cachorrinhos e tudo revolvem (...) e são muito travessos que não há viver com eles, e são de estima por essas e outras habilidades que têm". Pe. Anchieta, (1886 (1938: 432) ) 


\section{AGRADECIMENTOS ESPECIAIS}

Aos meus orientadores, professores e mais do que isso, amigos(as) de minha graduação Priscila Carvalho de Oliveira, por ceder toda a infraestrutura e por ser a Diretora do Hovet, Juliana Noda Bechara, por fazer parte de um mesmo grupo de trabalho, Angélica do Roccio, Jefferson Douglas, Ana Flávia de Carvalho, porque sem a sua contribuição não seria possível realizar esta pesquisa, João Flávio Martins, Maria Adriana Lobo, Maria Raquel Negro, Milton Kolber, entre outros pelo companheirismo, amizade, ensino, incentivo e por confiarem em meu trabalho. Esta vitória tem a contribuição dada por vocês, e representadas por mim.

A todos os meus amigos do Hospital Veterinário "Vicente Borelli", por me ajudarem nesta etapa, não medindo esforços em qualquer momento.

Aos meus professores da Pós-Graduação, Maria Angélica Miglino, por ter me aceito neste departamento oferecendo todo o conhecimento e dedicação que tem, Carlos Ambrósio (Caju) pela dedicação, ensinamentos e total colaboração Pedro Primo Bombonato, Arani Nanci Bonfim, Paula de Carvalho Papa, José Roberto Kfouri Júnior, Francisco Blazquez, João Stopiglia e Denise Fantoni, por todos os ensinamentos transmitidos.

A minha família, meus pais e irmãs Ana Laura (Lala) e Maria Gabriela (Gabi), meu cunhado (Ricado) e agora meu sobrinho Gabriel por estarem sempre ao meu lado e por me desejarem sempre o melhor.

As minhas avós materna Odeli e paterna Aparecida, aos meus avôs materno Grilo (in memorian) e Fortunato (in memorian), tias Terezinha, Duda, tio Grilinho, aos primos Juninho e Luquinha e a prima Bia, e a todos os outros tios(as), primos(as) e aos demais parentes de São João.

As minhas amigas da Residência Veterinária, Sylvinha, Vivi, Maria Claudia, Jú Amorin.

Aos meus colegas de graduação Tiago Carneiro, Telma Prado, Issac, Letícia, Helder, dentre muitos outros, que fizeram parte de meu crescimento.

Ao meu lindo e maravilhoso Cão, Yang Lord Buzon, pelos momentos mega divertidos que passamos juntos e também minha tarta (tartaruga). 
Aos meus colegas de pós graduação, Guilherme (Mamão), Rosa Cabral, Érika Branco, Vivi Samoto, por fazer parte de um grupo que me trouxe muito incentivo profissional, que depositaram em mim uma enorme confiança no trabalho em conjunto e muitas saudades de nossos protocolos.

Aos meus amigos Evander Bueno e Thiago Aloia, companheiros de república que sempre estavam comigo em todos os momentos,

Ao meu amigos de pós graduação Fernandinho Garbeloti, Flávio Maranhão, Eduardo e muitos outros amigos que não caberiam nesta lista e peço perdão por isso.

Os meus amigos de rapel, César Peres (Brucutu) e Mario Peres (Marinho), e seus pais Marcelo (Zezinho) e Cristina, que só nós mesmos sabemos o que passamos juntos nessas aventuras.

Aos funcionários da anatomia Maicon, Jaqueline e Índio, da biblioteca, Helena e Elza que representam a gentileza do trabalho de toda biblioteca.

A minha professora e orientadora Silvia, por ser uma pessoa puramente humana e por ter me ensinado tanto mesmo com tantos problemas. Obrigado pela recepção, amizade, e magnífica orientação, que somente me trouxe ânimo para seguir em frente diante de todos os obstáculos que surgiram por esse período.

Aos meus amigos que consegui formar ao longo de todo esse tempo em São Paulo e em outras regiões do Brasil. Obrigado e muitos outros que mesmo estando longe, guardo comigo lembranças boas de nossos momentos. Mais uma vez peço perdão por não ter posto aqui seus nomes. 


\section{RESUMO}

GREGORES, G. B. Topografia vértebro-medular e anestesia espinhal em quati (Nasua nasua). [Topographic anatomy of spinal cord and spinal anesthesia in coatimundi (Nasua nasua)]. 2006. 70 f. Dissertação (Mestrado em Ciências) Faculdade de Medicina Veterinária e Zootecnia, Universidade de São Paulo, São Paulo, 2006.

Objetivou-se com esta pesquisa descrever a topografia vértebro-medular do quati (Nasua nasua), com o intuito de assentar bases morfológicas que possam ser utilizadas em pesquisas como a anestesiologia, assim como, desenvolver técnicas de anestesia espinhal que possam ser empregadas na rotina clínico-cirúrgica veterinária. Este trabalho foi dividido em três etapas: a primeira correspondeu aos estudos morfológicos (anatomia), a segunda na contenção química e a terceira no desenvolvimento/avaliação da técnica de anestesia espinhal. Para os estudos morfológicos foram utilizados três animais adultos provenientes do criatório científico CECRIMPAS, da Faculdade de Medicina Veterinária da Fundação de Ensino Octávio Bastos - FEOB. Os animais já formolizados foram dissecados em toda a extensão da coluna vertebral até o acesso a medula espinhal. A segunda etapa consistiu no desenvolvimento/avaliação da contenção química, onde foram utilizados oito animais, os quais foram submetidos à contenção química com auxílio de cetamina-s $(20 \mathrm{mg} / \mathrm{kg})$ associada ao midazolam $(0,5 \mathrm{mg} / \mathrm{kg})$, administrados pela via intramuscular. A terceira etapa consistiu no desenvolvimento/avaliação da técnica de anestesia espinhal, onde se administrou a lidocaína $(4,0 \mathrm{mg} / \mathrm{kg}$ ) no espaço lombossacro. Foram avaliados os seguintes parâmetros: freqüência e ritmo cardíaco, freqüência respiratória, período de latência, hábil e recuperação, relaxamento muscular e analgesia para ambas as etapas de contenção química e analgesia espinhal. Os resultados evidenciaram que a topografia vertebral é dividida em cinco regiões, a medula espinhal apresenta-se como uma massa alongada, de coloração esbranquiçada. A técnica de anestesia espinhal, apresentou-se como uma técnica segura e eficaz, promovendo analgesia adequada e relaxamento muscular em toda a região pélvica.

Palavras-chave: Quati. Contenção animal (química). Anatomia animal. 


\begin{abstract}
GREGORES, G. B. Topographic anatomy of spinal cord and spinal anesthesia in coatimundi (Nasua nasua). [Topografia vértebro-medular e anestesia espinhal em quati (Nasua nasua)]. 2006. 70 f. Dissertação (Mestrado em Ciências) - Faculdade de Medicina Veterinária e Zootecnia, Universidade de São Paulo, São Paulo, 2006.
\end{abstract}

The objective of study was to describe the topography of spinal cord of the coatimundi (Nasua nasua), in order to obtain morphologic bases that can be used in an applied researches as anesthesiology, as well as, to develop techniques of spinal anesthesia techniques that can be used in the veterinary clinical-surgical routine. This study was divided in three stages: the first corresponded to the morphologic studies (anatomy), second in the chemical restraint and the third in the development/evaluation of the technique of spinal anesthesia. For the morphologic studies three coming adult animals of the scientific creation were used CECRIMPAS, of University of Veterinary Medicine of the Foundation of Ensino Octávio Bastos - FEOB. The animals already formaldenyde were dissected in the whole extension of the spine to the access the spinal marrow. The second stage consisted of the development/evaluation of the chemical restraint, where eight animals were used, which they were submitted to the chemical restraint with ketamine-s $(20 \mathrm{mg} / \mathrm{kg})$ associated to the midazolam $(0,5$ $\mathrm{mg} / \mathrm{kg}$ ), administered by intramuscular route. The third stage consisted of the development/evaluation of the technique of spinal anesthesia, where administered the lidocaine $(4,0 \mathrm{mg} / \mathrm{kg})$ in the space lombossacro. They were appraised the following parameters: rate and heart rhythm, respiratory rate, latency period, skilled and recovery, muscular relaxation and analgesia for both stages of chemical contention and spinal analgesia. The results evidenced that the vertebral topography is divided in five areas; the spinal marrow comes as a prolonged mass, of whitish coloration. The technique of spinal anesthesia, came as a safe and effective technique, promoting appropriate analgesia and muscular relaxation in the whole pelvic area.

Key words: Liver. Coatimundi. Animal restraint (chemical). Anatomy animal. 


\section{LISTA DE FIGURAS}

Figura 1 - Vista lateral de um esqueleto ósseo, referenciando as vértebras cervicais do quati (Nasua nasua)

Figura 2 - Vista lateral de um esqueleto ósseo, referenciando as vértebras torácicas do quati (Nasua nasua)

Figura 3- Vista lateral de um esqueleto ósseo, referenciando as vértebras lombares do quati (Nasua nasua)

Figura 4 - Vista lateral de um esqueleto ósseo, referenciando o sacro do quati (Nasua nasua)

Figura 5- Vista lateral de um esqueleto ósseo, referenciando as vértebras coccígeas do quati (Nasua nasua).

Figura 6 - Vista dorso lateral da medula espinhal, evidenciando a intumescência cervical do quati (Nasua nasu).

Figura 7 - Vista dorso lateral da medula espinhal, evidenciando a intumescência lombar do quati (Nasua nasua)...

Figura 8 - Vista dorso lateral da medula espinhal, evidenciando a membrana dura-máter da medula espinhal no quati (Nasua nasua).....

Figura 9 - Vista dorso lateral da medula espinhal, evidenciando com o número 1 a raiz dorsal e com o número 2 a raiz ventral do quati (Nasua nasua).

Figura 10 - Posição verticalizada em um ângulo de 90 graus, referenciando a posição da punção no espaço lombo-sacro. 


\section{LISTA DE TABELA}

Tabela 1 - Valores individuais, média e desvio padrão do período hábil da contenção química com cetamina-S e midazolam nos quati (Nasua nasua).

Tabela 2 - Valores individuais, médias e respectivos desvios-padrão da freqüência cardíaca (batimentos por minuto) dos quatis (Nasua nasua) anestesiados com cetamina-S e midazolam.

Tabela 3 - Valores individuais, médias e respectivos desvios-padrão da freqüência respiratória (movimentos respiratórios por minuto) dos quatis (Nasua nasua) anestesiados com cetamina-S e midazolam. 
1 INTRODUÇÃO

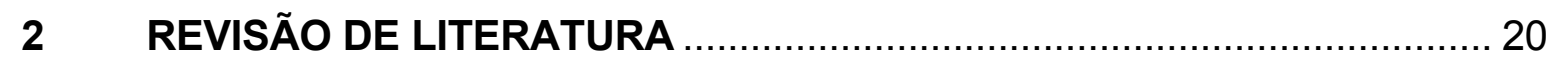

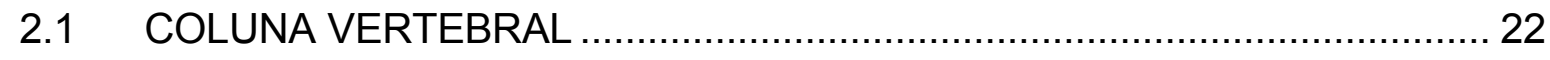

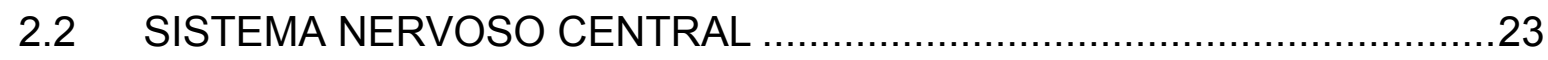

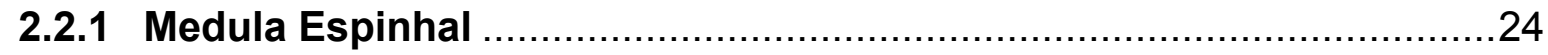

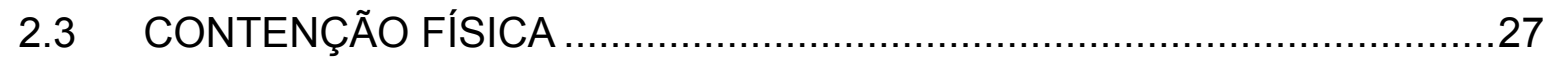

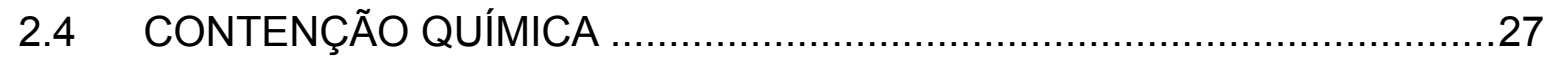

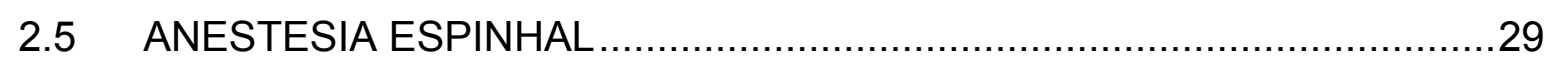

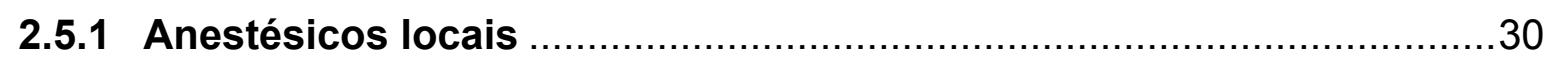

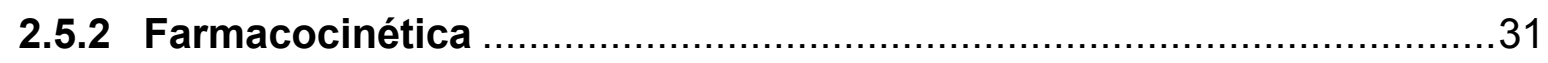

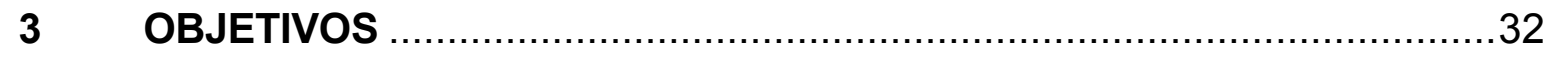

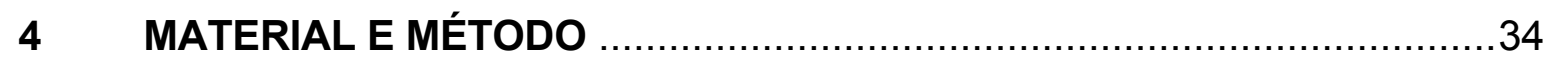

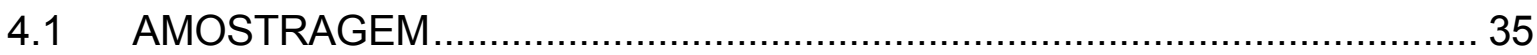

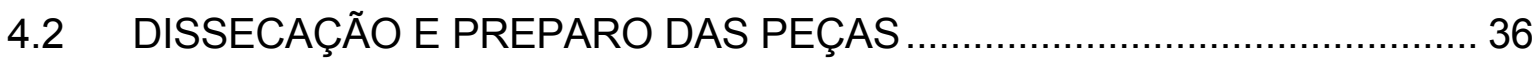

4.3 LAVAGEM SISTÊMICA E FIXAÇÃO DO MATERIAL.................................... 36

4.4 ACESSO DORSAL A COLUNA VERTEBRAL E MEDULA ESPINHAL....... 36

4.5 DESENVOLVIMENTO DA TÉCNICA DE ANESTESIA ESPINHAL COM BASE NA ANATOMIA MACROSCÓPICA E MESOSCÓPICA DA REGIÃO.......... 37

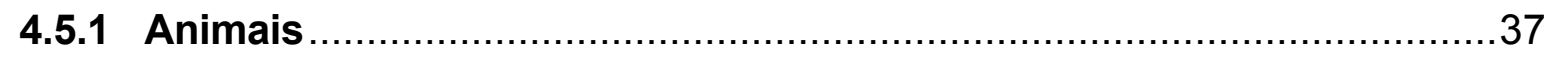

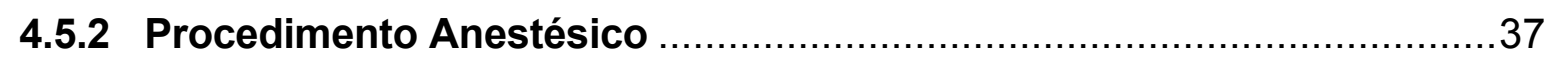

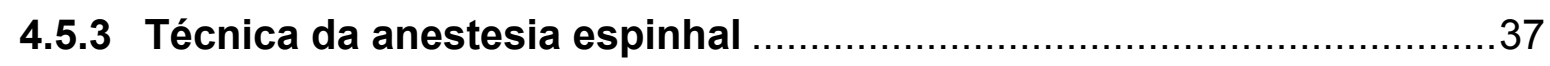

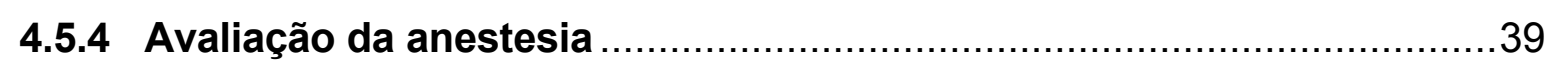

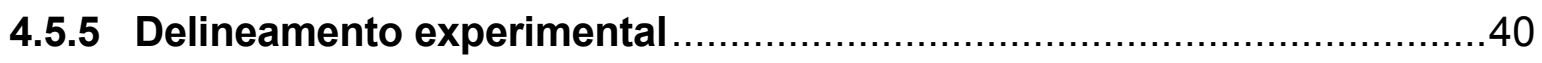

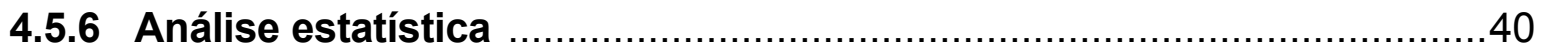

5 RESULTADOS

5.1 MORFOLOGIA DA COLUNA VERTEBRAL ………................................ 42

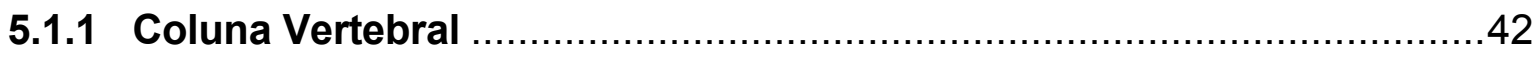

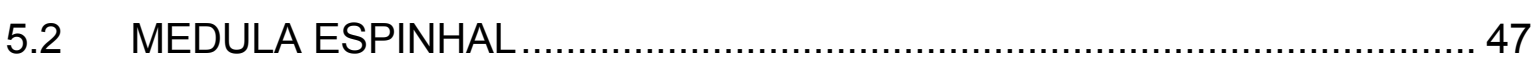

5.2.1 Intumescência cervical e Intumescência lombar ..................................47

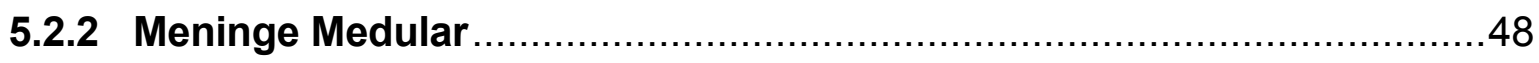

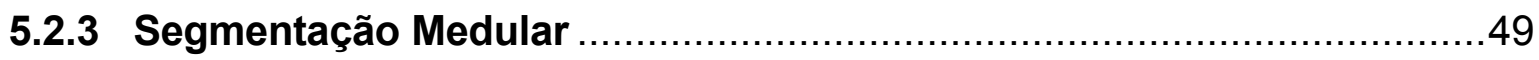




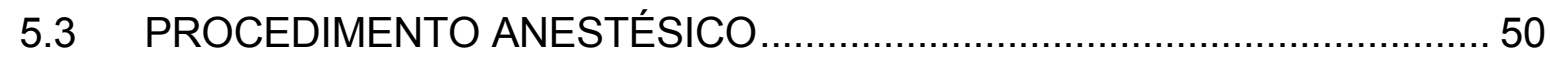

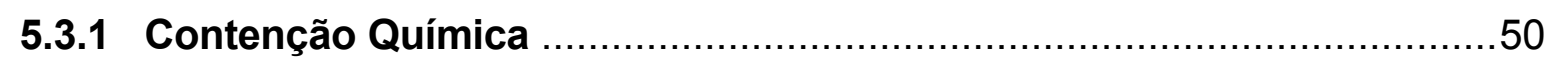

5.3.2 Período de Latência, Hábil e de Recuperação.......................................50

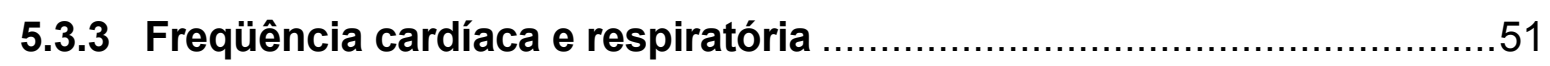

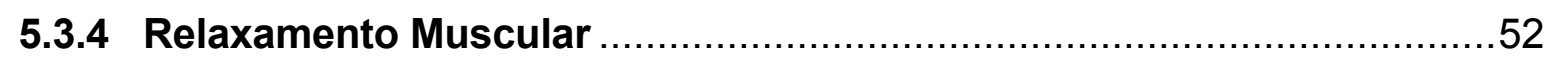

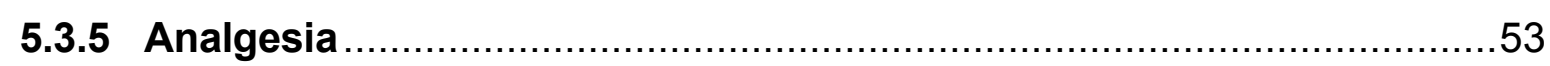

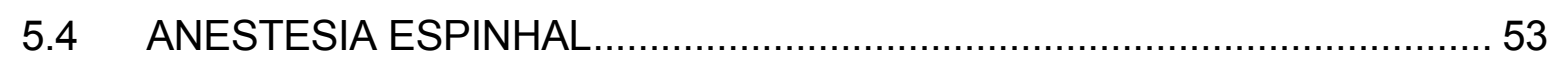

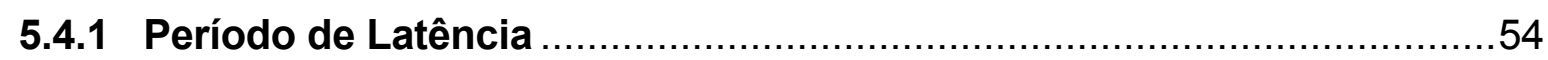

5.4.2 Período Hábil, Relaxamento muscular e Analgesia ..............................54

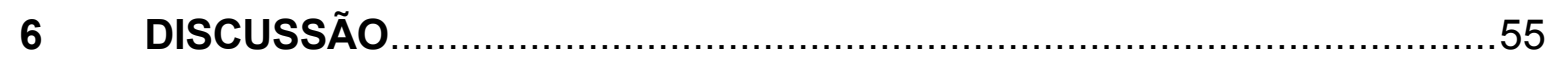

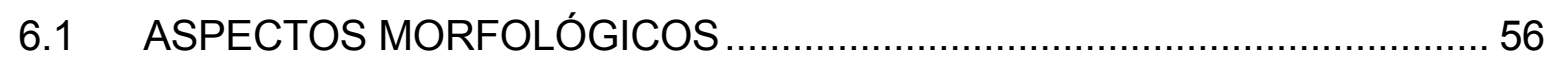

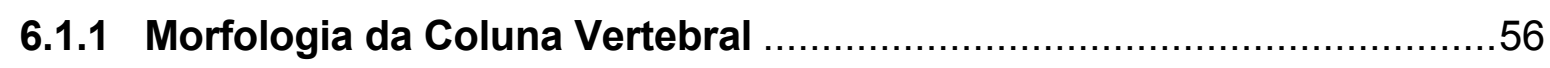

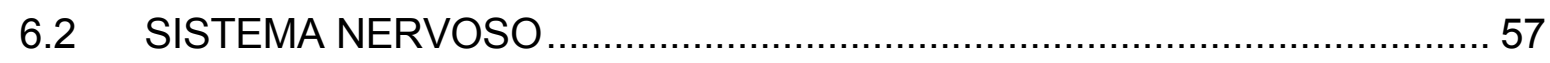

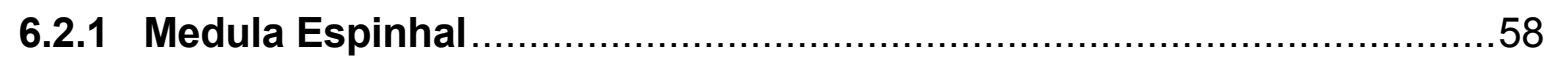

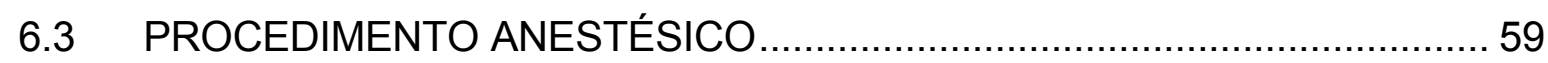

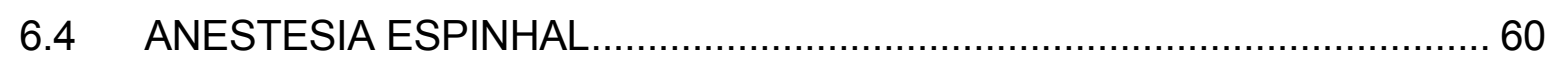

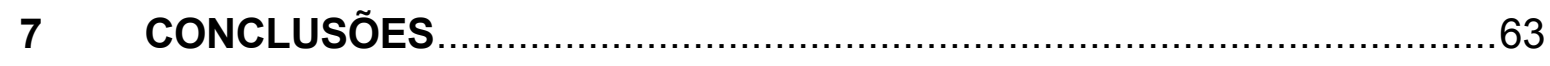

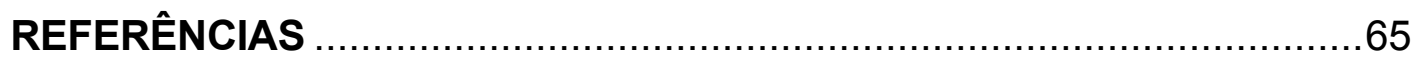




\section{INTRODUÇÃO}

A descrição do sistema nervoso dos animais silvestres é de fundamental importância para o conhecimento dos aspectos morfológicos dessas espécies, quer no sentido evolutivo, quer no sentido de fornecer embasamento para abordagens clínico-cirúrgico e comportamental. O conhecimento morfológico das relações entre a medula e a coluna vertebral é de importância para os médicos veterinários e biólogos, permitindo o conhecimento comparado a outras espécies silvestres e domésticas, principalmente no emprego de técnicas anestésicas e dentre elas a anestesia espinal (CARVALHO, 2004).

Um fator importante a ser considerado é, muitas vezes, o desconhecimento da distribuição da inervação sobre o sistema nervoso (ROCHA, 2003).

A espécie estudada neste trabalho pertence ao mesmo grupo dos mascarados assim como a mão pelada. Pertencem ao Filo Chordata, a Classe Mammalia, a ordem Carnivora e a Família Procyonidae. A Família Procyonidae possui 18 subespécies; no entanto quatro espécies são encontradas desde 0 Panamá (América Central) até a Argentina. A espécie Nasua nasua é localizada na América do Norte, Central e do Sul. Os procyonidae podem chegar a ter $30,5 \mathrm{~cm}$ de altura; seu comprimento varia entre $43-66 \mathrm{~cm}$ mais $22-69 \mathrm{~cm}$ de cauda, podendo atingir até $11 \mathrm{~kg}$.

$\mathrm{O}$ quati vive em grandes bandos formados de fêmeas e machos jovens. Na época de acasalamento, habitualmente no final da primavera, o macho dominante no centro do território de cada grupo de fêmeas começa aproximar-se desse mesmo grupo.

Procura-se com esta pesquisa descrever a topografia vértebro-medular do quati, pois é sabido que o conhecimento morfológico das relações entre a medula e a coluna vertebral é de extrema importância para o emprego da técnica de anestesia espinhal e/ou epidural, ou seja, assentar bases morfológicas para aplicá-las no desenvolvimento de técnica de anestesia espinhal, que consequentemente venham favorecer a clínica, anestesia e cirurgia veterinária dos quatis, e deste modo, gerar benefícios que acrescentem na qualidade do atendimento prestado a esses animais. 
Embora a literatura consultada relate técnicas anestésicas para os quatis, não é citada a anestesia espinhal. Sabe-se que a anestesia espinhal é uma técnica anestésica amplamente empregada no homem e em mamíferos de modo geral, apresentando-se como uma opção segura, e uma vez empregada adequadamente, proporciona menor grau de reações adversas. Além disso, trata-se de procedimento ideal para a realização da vasectomia ou deferentectomia, que é uma técnica de esterilização e está indicada para o controle populacional da espécie. 


\section{REVISÃO DE LITERATURA}

Quando se depara com inúmeros trabalhos sobre os quatis, observa-se a importância destes animais na disseminação de doenças para os animais domésticos e para o homem no Brasil.

Este carnívoro encontra-se distribuído geograficamente de maneira bem comum. Foram observados quatis na Floresta Atlântica (parque Estadual de Carlos Botelho - no Estado de São Paulo). A estrutura social dos quatis neste Parque foi semelhante à descrita na literatura. A estação de acasalamento inicia-se em agostosetembro e os filhotes nascem em outubro-novembro. Neste Parque se mostraram muito arbóreos diferentemente de outras populações descritas em outras regiões. Esta característica se dá pela forragem de bromélias existentes no estrato arbóreo. Estas plantas são adequadas para estes animais e são muito comuns na Floresta Atlântica e onde os quatis são observados. Estes achados sugerem que a espécie pode ajustar suas preferências nos diferentes ambientes e estratos de forragens sem mudar sua estrutura social básica (BEISIEGEL, 2001).

$\mathrm{Na}$ América do Norte, os trabalhos de maior relevância são referentes à fisiologia da respiração em toda a espécie Procyon. Boggs e Irvin (1992) estudaram os mecanismos respiratórios do coatimundi e woodchuck para determinar se há diferenças nos padrões respiratórios nestas duas espécies de tamanho e corpos semelhantes. $O$ trabalho constituiu em avaliar estática da complacência do sistema respiratório nas duas espécies, chegando a uma conclusão que não existiu diferença significativa entre as duas espécies. Grant et al. (1976) estudaram a regulação local de fluxo de sangue pulmonar e relações de ventilação-perfusão no coatimundi. Um estudo bastante interessante foi escrito por Mcclearn (1985) referente à anatomia do antebraço do guaxinim e dos músculos dos membros pélvicos do quati. 


\subsection{COLUNA VERTEBRAL}

Devido à carência de informações sobre a coluna vertebral e medula espinhal no quati (Nasua nasua), a revisão será realizada em relação ao cão e do gato. A coluna vertebral (ou espinha) estende-se do crânio até a ponta da cauda. Consistem em uma grande quantidade de ossos separados, as vértebras, unidos de forma estável, porém não rígida. A coluna vertebral envolve e protege a medula espinhal, resguarda as estruturas do pescoço, tórax, abdômen e pelve.

As vértebras, em sua maioria, obedecem a um padrão comum ao qual se sobrepõem características que distinguem as várias regiões: cervicais, torácicas, lombares, sacrais e caudais (coccígeas). Os números de vértebras que compõem estas regiões em cão são: sete cervicais, 13 torácicas, sete lombar, três sacrais e de 20 a 23 coccígeas e no gato com a mesma numeração tendo uma redução das vértebras lombares para seis, as vértebras coccígeas os ossos são mais finos e diferem dos cães de maneira sutil, que é fácil de perceber e difícil de definir (DYCE; SACK; WENSIWG, 2004).

As vértebras cervicais são classificadas como a primeira o atlas, a segunda o axis e são bastante modificadas para permitir o livre movimento da cabeça. $O$ atlas possui um pequeno corpo, duas massas laterais unidas por um arco dorsal e ventral. O axis é a vértebra mais longa, possuem em processo espinhoso muito alto, os processos transversos são grandes, as vértebras cervicais restantes tornam-se mais curtas. O processo transverso ramifica-se em tubérculos dorsal e ventral, o processo espinhoso é pouco desenvolvido exceto na última. As vértebras torácicas articulamse com as costelas e correspondem às mesmas em número. Em cães pequenos, as variações no número das vértebras não são raras, sendo compensadas muitas vezes por uma modificação recíproca na região lombar que deixa toda a coluna toracolombar inalterada. Os corpos vertebrais curtos com extremidades achatadas, processos transversos com tuberosidades das costelas, com extremidades curtas e grossas (DYCE; SACK; WENSIWG, 2004).

As vértebras lombares diferem das vértebras torácicas no comprimento maior e no formato mais uniforme de seus corpos. Ausência de facetas costais, processos transversos achatados e longos que se projetam lateralmente, processos 
espinhosos com uma altura menor e geralmente uma inclinação anterior (DYCE; SACK; WENSIWG, 2004).

Após a coluna lombar, o sacro é formado pela fusão de várias vértebras, se estreita a partir da sua extremidade cranial para a caudal, face dorsal com quantidade peculiar de processos espinhosos, processos transversos fundidos e na sua extremidade cranial a superfície articular para o íleo (DYCE; SACK; WENSIWG, 2004).

As vértebras coccígeas variam muito, mesmo dentro de uma espécie. As primeiras vértebras se parecem com as vértebras lombares em miniatura, os elementos centrais e posteriores da série são reduzidos a simples hastes (DYCE; SACK; WENSIWG, 2004).

\subsection{SISTEMA NERVOSO CENTRAL}

O sistema nervoso é "como um mecanismo complexo, mediante o qual o organismo se comporta em relação com o mundo exterior, e, por meio da qual, se coordena a função de suas diversas partes". (SISSON; GROSSMAN, 1979). A medula espinhal e o cérebro constituem o sistema nervoso central. A medula espinhal fica enclausurada no canal vertebral, formado por uma série de ossos protetores (as vértebras cervicais, torácicas e lombares) dispostos de maneira a formar este canal ou conduto funcional onde estão as raízes espinhais dorsal e ventral que pertencem ao sistema nervoso periférico (CUNNINGHAM, 2004).

Através das raízes e dos nervos espinhais, a medula inerva o tronco e cauda, os membros e a superfície caudal e dorsal da cabeça. Dentro do canal espinhal, os nervos motores e sensitivos estão separados; os nervos sensitivos penetram na medula espinhal através das raízes nervosas dorsais, e transmitem impulsos sensoriais (aferentes) para a medula, enquanto que, os nervos motores deixam a medula espinhal por meio das raízes ventrais que carreiam a saída de respostas através de impulsos (eferentes) vindos da medula para músculos e glândulas (CUNNINGHAM, 2004; FLETCHER, 1993). 
O sistema nervoso é composto por dois tipos de células: neurônios (células nervosas), que recebem e transmitem informações; e células da glia que sustentam, mantêm os neurônios no lugar e impedem os impulsos nervosos de se dispersarem entre as células nervosas que não são unidas através de sinapse. Estes dois tipos de células são conectados ao tecido vascular, e é subdividido em Sistema Nervoso Central (SNC), consistindo no cérebro (encéfalo) e espinha dorsal (medula espinhal), e o Sistema Nervoso Periférico (SNP), composto de nervos cranianos e espinhais. As divisões são arbitrárias porque partes do mesmo neurônio podem estar no SNC e no SNP. O termo nervo é aplicado à estrutura total que consiste em processos periféricos de células nervosas ligadas em série e envoltas por tecido conjuntivo. Gânglio é o termo aplicado a uma coleção de corpos de células nervosas, de estrutura esférica envolto por tecido conjuntivo associado com um nervo, fora do SNC. Fibra nervosa é um termo utilizado para descrever um processo microscópico de uma célula nervosa. As estruturas contidas dentro do SNC estão localizadas dentro da membrana neuroglial do cérebro ou da espinha dorsal; assim, as raízes e gânglios, normalmente ilustrados com o SNC pertencem ao SNP e não ao SNC. O tecido nervoso é dividido em massa branca e cinzenta, baseado na aparência de partes frescas seccionadas do SNC. A massa cinzenta consiste principalmente em corpos de células nervosas, neuroglia, dendritos e axônios entrelaçados, mielinizados e não mielinizados. A parte branca consiste em fibras mielinizadas dispostas longitudinalmente e neuroglia associada (KITCHELL; EVANS, 1993).

\subsubsection{Medula Espinhal}

A medula espinhal é uma estrutura alongada, mais ou menos cilíndrica, mas com algum achatamento dorso-ventral e determinadas variações regionais de forma e dimensões. As variações mais importantes são os espessamentos (intumescências) das partes que dão origem aos nervos que suprem os membros anteriores (torácico) e posteriores (pélvico) e o afilamento final caudal (cone medular). A medula é dividida em segmentos correspondentes aos somitos por origens seriadas das raízes dos nervos espinhais pares. O encéfalo e a medula 
espinhal ficam contidos dentro de um espaço contínuo conferido pela cavidade do crânio e pelo canal formado por sucessivos anéis ósseos e ligamentos e discos de união da coluna vertebral. O canal é mais largo dentro do atlas e vai diminuindo rapidamente dentro do sacro; ao longo de seu comprimento, expande-se mais onde contém as intumescências cervical e lombar da medula espinhal, das quais emergem os nervos que formam os plexos dos membros (DYCE; SACK; WENSIWG, 2004).

A topografia da medula espinhal é de importância muito considerável na clínica veterinária, já que frequentemente aplicam-se injeções no canal, em particular de solução de anestésico local, com a finalidade de bloquear nervos espinhais específicos. Mesmo com as inclusões de seus envoltórios meníngeos, a medula espinhal é consideravelmente menor do que o canal vertebral e mais curto. O desvio relativo na posição (ascensus medullae) leva os segmentos da medula cranialmente com relação às suas posições originais dentro das vértebras de mesmas designações numéricas. O desvio dos segmentos mais caudais é mais pronunciado e explicam o arranjo peculiar de nervos espinhais associados. Estes assumem trajetos progressivamente mais longos dentro do canal, indo alcançar seus forames fixos de saída e formando uma cauda (conhecida como cauda eqüina por sua semelhança superficial com a cauda de um cavalo) para cada lado do cone medular (DYCE; SACK; WENSIWG, 2004).

O nível em que a medula termina varia entre as espécies e com a idade. No cão ocorre em $L_{6}$ a $L_{7}$. Através do canal vertebral a medula e as raízes espinhais são "envelopadas" por três camadas (membranas) protetoras contínuas chamadas de meninges, que apresentam determinadas diferenças topográficas importantes em suas partes craniais e vertebrais. A membrana rígida mais externa é a dura-máter é fibrosa e forte e funde-se com o periósteo mais interno dos ossos do crânio, separase deste no forame magno, formando um tubo livre separado do canal vertebral por um espaço epidural amplo, embora variável. Ao redor da dura-máter localiza-se o outro espaço freqüentemente usado pelos anestesiologistas, o espaço epidural, sendo este limitado externamente pelo periósteo vertebral, ligamento amarelo e ligamento longitudinal. O conteúdo do espaço epidural inclui as raízes nervosas que passam através dos foramens para localizações periféricas, tecido adiposo frouxo, 
tecido aureolar, vasos linfáticos e um denso plexo nervoso (DYCE; SACK; WENSIWG, 2004; FLETCHER, 1993).

O tubo dural é fixado em sua extremidade caudal, onde a diversa meninge finalmente combina-se com um cordão fibroso (filamento terminal), que se funde na superfície superior das vértebras caudais. A fusão da dura máter craniana com o periósteo oblitera o espaço epidural dentro do crânio e seios venosos cranianos ficam desta forma, embutidos dentro da espessura da membrana composta. Além de recobrir a cavidade a dura-máter craniana forma determinadas pregas que se projetam para dentro e limitam os movimentos oscilatórios do encéfalo. Um espaço capilar separa a dura-máter da aracnóide, a primeira das duas membranas internas mais delicadas (DYCE; SACK; WENSIWG, 2004; MAILHAC; CHAFFAUX; ALVAREZ, 1996; SCHIMIDT; OECHTERING, 1993).

Dellmann e McClure (1975) descrevem a medula espinhal dos carnívoros: "a intumescência cervical inclui o quinto segmento da medula espinhal cervical até o segundo segmento da medula espinhal torácica. A intumescência lombar tem início no quarto segmento lombar e termina no segundo segmento sacral com a medula espinhal afunilando-se até o cone medular. A medula espinhal termina muito próxima da junção da sexta e sétima vértebras lombares. $O$ tamanho e o formato, em corte transversal, da medula espinhal do canino variam em diferentes níveis. O trato corticospinhal compõe 10\% da substância branca da medula espinhal no cão. As fibras do trato corticospinhal estão distribuídas ou termina na medula espinhal conforme segue: para a parte cervical $50 \%$; para a parte torácica $20 \%$, e para a parte lombar $30 \%$ ".

Sobre as meninges citam que, "no cão, o filamento da duramáter espinhal está inserido no periósteo do canal espinhal da sétima ou oitava vértebras caudais. A cavidade subaracnóidea termina caudalmente no nível da primeira vértebra sacral. Os tubos da dura-máter espinhal, que circundam as raízes dorsal e ventral dos nervos espinhais, estão normalmente aderidos um ao outros nos primeiros cinco segmentos cervicais. As serrações do ligamento dentriculado da pia máter são grandes e estende-se caudalmente até o primeiro segmento sacral da medula espinhal. A última serração insere-se na dura-máter ao nível do corpo da quinta vértebra lombar, entre o quinto e o sexto nervos espinhais lombares". 
A medula espinhal no cão é quase circular em secção transversal, exceto nas intumescências cervical e lombar, onde está comprimida dorso-ventralmente. O cone medular se acha em cima da união da sexta e sétima vértebras lombares. A extensão da medula em cães mede em média 38 centímetros; destes, 11 centímetros correspondem à região cervical, 17,4 centímetros à região torácica, sete centímetros à região lombar e 2,6 centímetros à região sacrococcígea (SISSON; GROSSMAN, 1979).

\subsection{CONTENÇÃO FÍSICA}

A contenção física antecede a imobilização química, devendo a primeira ser efetuada por meio de equipamentos adequados, ou seja, no caso dos quatis é utilizado o pau-de-couro ou chamado de "cambão", que se trata de uma haste medindo cerca de 1,30 m de comprimento, que possui um laço de couro preso na extremidade distal. O animal é laçado, a ponta livre é puxada o suficiente para manter sua cabeça fixa e a distância do operador, e posteriormente deita-se o animal no solo para facilitar a injeção do agente (DINIZ, 2002).

\subsection{CONTENÇÃO QUÍMICA}

A cetamina é representante da classe das fenciclidinas que se encontra atualmente em uso clínico. O amplo emprego deste agente em Medicina Veterinária deve-se ao fato de possuírem elevada margem de segurança, por haver a possibilidade de administração por outras vias além da intravenosa e por serem utilizados em inúmeras espécies de animais domésticos e silvestres (FANTONI; CORTOPASSI; BERNARDI, 2002).

A cetamina apresenta-se como mistura racêmica de dois isômeros individuais que diferem em potência anestésica. É hidrossolúvel e a solução aquosa a $10 \%$ tem 
pH de 3,5. Devido a esta acidez, possui propriedades irritantes quando administrada pela via intramuscular, não promovendo edema ou necrose tecidual. É bastante lipossolúvel sendo rapidamente absorvida após sua administração sendo utilizados em inúmeras espécies de animais domésticos e silvestres (FANTONI; CORTOPASSI; BERNARDI, 2002).

A cetamina tem ações complexas e não totalmente compreendidas na neurotransmissão do SNC. Bloqueiam os receptores muscarínicos dos neurônios centrais e podem potencializar os efeitos inibitórios do GABA. Interagem com os receptores colinérgicos centrais atuando como antagonista e com receptores opióides agindo como agonistas. O aumento da atividade motora é causado pelo aumento da concentração cerebral de dopamina e serotonina, o mesmo ocorrendo com a hipertonicidade muscular. A analgesia causada pela cetamina é atribuída ao bloqueio da condução de impulsos dolorosos ao tálamo e áreas corticais. Não há perda de reflexos protetores, os olhos permanecem abertos, as pupilas midriáticas e há ausência de relaxamento muscular. A hipertonia muscular é comum com a cetamina, sobretudo se administrada isoladamente (FANTONI; CORTOPASSI; BERNARDI, 2002).

O efeito deletério excitatório da cetamina é eliminado ou minimizado pela administração conjunta de sedativos ou tranqüilizantes. Os derivados benzodiazepínicos, como o midazolam, reduzem os efeitos excitatórios da cetamina, pois promovem relaxamento muscular e hipnose (HELLYER; FREEMAN; HUBBELL, 1991).

Susko et al. (2000) estudaram a utilização da cetamina em oito cães saudáveis distribuídos aleatoriamente em dois grupos utilizando dois protocolos diferentes: os dois grupos foram pré-tratados com $0,05 \mathrm{mg} / \mathrm{kg}$ de acepromazina e $0,3 \mathrm{mg} / \mathrm{kg}$ de midazolam pela via intramuscular. O primeiro grupo recebeu $5 \mathrm{mg} / \mathrm{kg}$ de cetamina-s intravenoso e o segundo recebeu $12 \mathrm{mg} / \mathrm{kg}$ de cetamina-s intramuscular. Concluíram que o uso intravenoso na dose apresentada seria adequado para procedimentos ambulatoriais e radiográficos, enquanto que a dose intramuscular seria suficiente para procedimentos como suturas de pele.

A molécula de cetamina possui um centro quiral que produz dois isômeros ópticos ou enantiômeros: uma forma dextrógera ou cetamina $S(+)$ e a forma 
levógera ou cetamina R (-) (WHITE et al., 1980). Como citado anteriormente, a cetamina geralmente é encontrada sob a forma de mistura racêmica, isto é, mistura composta pelos dois isômeros. Segundo HARLEY e GIDLEY (1970), essa mistura não necessita ser composta em proporções iguais de cada isômero.

WHITE et al. (1980) sugeriram, através de estudo clínico comparativo entre os efeitos dos isômeros e da mistura racêmica em voluntários humanos, que existem diferenças quantitativas e qualitativas entre os enantiômeros, no que se refere aos seus efeitos no SNC e sistema cardiopulmonar durante a anestesia.

O mesmo estudo determinou que quando o isômero $S(+)$ ou a cetamina racêmica foram infundidos para induzir a anestesia, um progressivo decréscimo na amplitude e freqüência do eletroencefalograma (EEG) ocorreu, tendo ocorrido o oposto com relação ao isômero $R(-)$.

O midazolam é classificado como um benzodiazepínico. Promove efeitos miorrelaxantes, ansiolíticos, anticonvulsivante e hipnótico, promovendo sono semelhante ao fisiológico, o que é bastante desejável na anestesia. Possui lipossolubilidade alta sendo rapidamente absorvido. Sua biotransformação ocorre por reações oxidativas, é hidrossolúvel, com meia-vida de 1,3 a 2,2 horas, não promovendo efeitos periféricos importantes, o que os torna amplamente empregados na indução da anestesia (CORTOPASSI; FANTONI, 2002; SPINOSA; GÓRNIAK, 2002).

\subsection{ANESTESIA ESPINHAL}

A anestesia espinhal (epidural ou peridural) é obtida por injeção de anestésico local no espaço epidural, espaço compreendido entre a dura-máter e o canal vertebral. Trata-se de técnica anestésica consagrada, que tem como principais vantagens a segurança, eficiência e custo baixo. Vale lembrar que a anestesia espinhal não está livre de efeitos deletérios e complicações. Sua alteração cardiovascular é facilmente compensada em animais hígidos, podendo ser 
irreversível em paciente com estas alterações. De toda a forma é necessária uma avaliação cuidadosa do quadro clínico antes de se optar por esta anestesia, (INTELIZANO et al., 2002).

A anestesia espinhal pode ser realizada mediante dois tipos de bloqueio, tais como: o bloqueio epidural e subaracnóideo. Estes bloqueios quando bem indicados, oferecem anestesia de boa qualidade, com poucos efeitos adversos ao paciente. $O$ bloqueio epidural é mais utilizado quando é preciso uma analgesia pós-operatória maior. O bloqueio subaracnóideo é uma técnica utilizada quando se deseja um bloqueio rápido, para procedimento de curta duração (GREENE, 1982; ORTENZI; TARDELLI, 1996).

\subsubsection{Anestésicos locais}

O principal anestésico local começou a ser estudado desde os meados de 1860, onde os pesquisadores Sigmund Freud e Karl Koller extraíram do arbusto andino Erytroxylon coca, um principio ativo denominado cocaína sendo o primeiro anestésico local descoberto. Posteriormente vários outros anestésicos locais foram introduzidos, incluindo a tetracaína em 1932 e a cloroprocaína em 1955 classificados como amino-ésteres. Em 1943, a lidocaína foi sintetizada por Lofgren, e sua introdução clínica um ano depois, marcou o primeiro uso de uma nova classe de anestésicos locais, as amino-amidas, derem continuidade a outros agentes desse grupo incluindo a mepivacaína (1956), bupivacaína (1957), prilocaína (1959), etidocaína (1971) e ropivacaína (1989) (CORTOPASSI; FANTONI; BERNARDI, 2002).

Os anestésicos locais são agentes que bloqueiam reversivelmente a condução nervosa, quando aplicados localmente no tecido nervoso em concentração apropriada. Possui grande vantagem por seu efeito ser reversível, não provocando danos estruturais nas células ou fibras nervosas (CORTOPASSI; FANTONI; BERNARDI, 2002). 


\subsubsection{Farmacocinética}

O anestésico local atravessa as membranas do nervo por difusão, obedecendo ao gradiente de concentração que depende basicamente da lipossolubilidade do medicamento, do pH do meio e da concentração do medicamento. Sob condições habituais de administração, o pH das soluções dos anestésicos locais é trazido para aquele dos líquidos extracelulares $(\mathrm{pH}=7,4)$, sem levar em consideração o $\mathrm{pH}$ da solução injetada. Como os anestésicos são bases fracas com o pKa que varia de 8 e 9, no $\mathrm{pH}$ dos tecidos, os anestésicos locais tendem a ficar em maior proporção na sua forma ionizada, tendo portanto, maior dificuldade de atravessar as barreiras celulares. No entanto, é esta forma ionizada que é responsável pelo efeito anestésico local (CORTOPASSI; FANTONI; BERNARDI, 2002).

O mecanismo de ação da anestesia epidural produzida por anestésico local é resultado da combinação de três mecanismos potenciais. Os anestésicos locais podem espalhar-se na área paravertebral, através do forame intervertebral e bloquear ramos nervosos distais às bainhas durais (de cada forame), resultando em bloqueio paravertebral múltiplo. O segundo mecanismo envolve a difusão do anestésico ao local através da dura-máter, dentro do espaço subaracnóide, dentro do qual bloqueia as raízes nervosas. Finalmente, após difusão através da duramáter, o anestésico local pode agir diretamente sobre a medula espinhal. Imagina-se que o local primário de ação dos anestésicos locais sejam as raízes nervosas, resultando em anestesia local. Esta teoria de bloqueio enquadra-se no efeito da gravidade (TORSKE; DYSON, 2000).

O tempo que leva para que o anestésico local penetrar no ramo nervoso e a concentração do fármaco atinjam níveis ideais, varia inversamente com o diâmetro do ramo. Nervos simpáticos são atingidos primeiramente, seguidos por nervos sensitivos e finalmente por nervos motores (TORSKE; DYSON, 2000).

A anestesia produzida por injeção epidural persiste até que o fármaco seja localmente absorvido. Os anestésicos altamente lipossolúveis são absorvidos em proporção muito mais lenta, resultando em efeito muito mais longo (TORSKE; DYSON, 2000). 


\section{OBJETIVOS}

O objetivo deste trabalho consistiu em:

- Descrever a topografia vértebro-medular do quati (Nasua nasua) por meio da macroscopia;

- Contribuir com estudo da anatomia comparada de animais silvestres;

- Desenvolver e padronizar a técnica de anestesia espinhal para a espécie em questão. 


\section{MATERIAL E MÉTODO}

Antes do início da descrição metodológica desta pesquisa, é importante salientar que a metodologia utilizada encontra-se dentro das normas da Comissão de Bioética de experimentação animal da Faculdade de Medicina Veterinária e Zootecnia da Universidade de São Paulo, protocolo sob n 954/2006. Além, disso, os protocolos farmacológicos adotados para esta dissertação contam com a autorização do IBAMA (Instituto Brasileiro do Meio Ambiente e de Recursos Naturais Renováveis) mediante licença $n^{\circ}$ 02027.007.222/02-80.

Esta pesquisa foi realizada em duas fases, as quais compreenderam:

- Dissecação e preparo das peças.

- Desenvolvimento de técnica de anestesia espinhal.

\subsection{AMOSTRAGEM}

A amostragem foi composta de três animais adultos, machos, pesando entre quatro a seis quilos, com diferentes idades, provenientes do Criatório Científico CECRIMPAS, da Faculdade de Medicina Veterinária da Fundação de Ensino Octávio Bastos - FEOB, após óbito por causas naturais, para a dissecação e preparo das peças. Foram utilizados também oito animais adultos, machos, pesando entre 4,9 a 6,5 kg, provenientes do Criatório Científico - CECRIMPAS, da Faculdade de Medicina Veterinária da Fundação de Ensino Octávio Bastos - FEOB, para o desenvolvimento de técnica de anestesia espinhal. 


\subsection{DISSECAÇÃO E PREPARO DAS PEÇAS}

Esta etapa do experimento foi realizada junto ao Laboratório de Anatomia Veterinária da Fundação de Ensino Octávio Bastos - FEOB e do Laboratório de Anatomia Veterinária da Faculdade de Medicina Veterinária e Zootecnia de São Paulo - FMVZ- USP.

\subsection{LAVAGEM SISTÊMICA E FIXAÇÃO DO MATERIAL}

Depois de constatado o óbito dos animais, foram dissecadas as artérias carótida comum e canuladas para lavagem de todo o sistema circulatório com solução salina aquecida a $37^{\circ} \mathrm{C}$, para facilitar a retirada do sangue coagulado. Após a lavagem, foi administrada na mesma artéria a solução de formaldeído a $20 \%$, para preservação do material. Em conjunto com a administração intra-arterial de formol foram aplicadas injeções intramusculares de formaldeído a 10\% com agulha $27 \times 8$ em toda a musculatura do pescoço, membros e cauda, para melhor fixação da peça. Durante a lavagem do sistema circulatório o animal foi mantido em decúbito lateral para facilitar a drenagem do sangue que saia pela veia jugular contralateral.

\subsection{ACESSO DORSAL A COLUNA VERTEBRAL E MEDULA ESPINHAL}

Decorrido o processo de fixação do material, os animais foram lavados em água corrente por uma hora, e em seguida, iniciou-se o processo de dissecação. Foi realizada tricotomia em toda a região dorsal da coluna, desde a região cervical até a região caudal.

Após tricotomia, realizou-se a incisão da pele. Por meio de materiais cirúrgicos realizou-se a divulsão do tecido subcutâneo e adjacente, até a região 
óssea dos processos espinhosos dos corpos vertebrais. Em seguida, já localizado e totalmente divulsionado os tecidos adjacentes de cada corpo vertebral é que se iniciou a osteotomia dos processos espinhosos e corpos vertebrais dorsal, para ter a visualização completa da medula espinhal em todo o seu trajeto.

\subsection{DESENVOLVIMENTO DA TÉCNICA DE ANESTESIA ESPINHAL COM BASE NA ANATOMIA MACROSCÓPICA E MESOSCÓPICA DA REGIÃO.}

Para a correta certificação do local do espaço epidural, foi realizada a dissecação dos animais já formolizados para não ocorrer equívoco na hora da anestesia epidural, já que não foi encontrado referencia para a tal.

\subsubsection{Animais}

Os animais foram submetidos a exame hematológico seriado, sendo escolhidos aqueles que não apresentaram alteração. Da mesma forma, foram selecionados apenas aqueles que não apresentavam lesões cutâneas que pudessem comprometer a punção lombossacra.

\subsubsection{Procedimento Anestésico}

O procedimento anestésico foi desenvolvido em duas etapas: inicialmente foi realizada a contenção física, uma vez que tais animais não aceitam nenhum tipo de manipulação ou contato com o ser humano. A segunda etapa foi estabelecer um protocolo anestésico para a correta contenção química para estes animais. O procedimento teve início com a captura destes animais no seu recinto, por meio de 
puçá e cambão, colocados em gaiola de contenção e levados ao Hospital Veterinário. No Hospital foram pesados separadamente em uma balança digital e por meio do peso, os fármacos foram calculados para a realização da contenção química.

Os animais foram submetidos a jejum alimentar de 12 horas e hídrico de cinco horas. Utilizou-se a cetamina- $\mathrm{S}^{1}$ na dose de $20 \mathrm{mg} / \mathrm{kg}$ associada ao midazolam ${ }^{2}$ na dose de $0,5 \mathrm{mg} / \mathrm{kg}$ aplicados pela via intramuscular, na região posterior ou caudal do músculo semimenbranoso e/ou semitendinoso, uma vez que estes músculos foram classificados assim pela aparência, inserção e sua localização parecida com os dos cães. Logo em seguida, os animais foram colocados em decúbito lateral para receberem um cateter intravenoso na veia cefálica para administração de solução de Ringer com lactato no volume de $5 \mathrm{ml} / \mathrm{kg} / \mathrm{hora}$.

\subsubsection{Técnica da anestesia espinhal}

Os animais foram submetidos ao decúbito esternal em posição de esfinge com os membros pélvicos estendidos para frente visando maior abertura do espaço intervertebral, facilitando, assim, a introdução da agulha. Por meio de dissecação prévia das peças, foi determinada a necessidade da localização das tuberosidades ilíacas, com os dedos polegar e o terceiro dedo, e do processo espinhoso da quinta ou sexta vértebra lombar. Caudalmente a este processo, e cranial aos processos espinhosos do sacro observou-se uma depressão, determinando assim o espaço lombossacro. Após a localização do espaço lombossacro os animais foram submetidos à tricotomia com a máquina de tosa e assepsia da região com povedine degermante e álcool a $70 \%$. Foram devidamente cobertos com panos de campo cirúrgicos, para evitar qualquer tipo de contaminação. Foi utilizado o mandril do cateter intravenoso de numero $20 \mathrm{G}$ para a punção.

A punção segue seqüencialmente as camadas: da pele, subcutâneo,

\footnotetext{
${ }^{1}$ Ketamin-S - Cristália, São Paulo/SP

${ }^{2}$ Dormire - Cristália, São Paulo/SP
} 
musculatura e o ligamento intervertebral. O fármaco empregado na anestesia epidural foi cloridrato de lidocaína ${ }^{3}$ na dose de $4,0 \mathrm{mg} / \mathrm{kg}$.

\subsubsection{Avaliação da anestesia}

Foram avaliados os seguintes atributos:

- Freqüências cardíaca e respiratória: os parâmetros cardiorrespiratórios foram avaliados por meio do fonedoscópio.

- Relaxamento muscular: foi avaliado por meio da resistência à flexão de membros, da resistência à abertura da boca e da observação de atividade muscular não induzida, segundo o escore proposto: [3 = intenso (flacidez muscular total); 2 = regular (discreto tônus muscular); 1 = leve (importante tônus muscular), e 0 = ausente (contrações durante manipulações)].

- Analgesia: foi avaliada para a anestesia espinhal por meio do estímulo doloroso induzido por pinçamento interdigital dos membros pélvicos e por estímulo ao reflexo anal, seguindo o escore: [ $3=$ intensa (reações importantes durante ao procedimento); 2 = moderada (eventuais reações durante 0 procedimento); 1 = leve (mínimas reações durante o procedimento) e $0=$ ausente (ausência de reações durante o procedimento)].

- Avaliação dos períodos de latência, hábil e recuperação

O período de latência foi determinado pelo tempo compreendido entre a administração do fármaco e a perda do tônus postural. O período hábil foi considerado como o intervalo de tempo em que o animal permaneceu completamente imobilizado. O período de recuperação foi considerado desde o retorno de sensibilidade até a primeira tentativa de endireitamento. 
- Qualidade da anestesia: nos momentos de indução e recuperação, verificouse a presença de vocalização, movimentos de pedalagem, defecação, salivação e miç̧ão assim como excitação e ataxia.

\subsubsection{Delineamento experimental}

Os parâmetros descritos foram mensurados a cada cinco minutos após a administração do fármaco até a recuperação completa.

\subsubsection{Análise estatística}

Para fins de análise estatística, apenas os valores avaliados aos cinco, 10, $20,30,40,50$ e $60 \mathrm{~min}$ foram confrontados. Os valores paramétricos foram analisados estatisticamente por meio do teste $T$ de Student para a comparação entre os grupos e análise de variância (ANOVA) seguida do teste de Tukey, sendo o grau de significância instituído de $5 \%(p<0,05)$. Os testes foram realizados em programa de computador ${ }^{4}$.

\footnotetext{
${ }^{4}$ Instat, Graphpad Software, USA
} 


\section{RESULTADOS}

Para elucidar melhor os resultados deste estudo, foram determinadas subdivisões que compreenderam respectivamente os estudos referentes aos aspectos morfológicos (anatomia), a contenção química e a anestesia espinhal.

\subsection{MORFOLOGIA DA COLUNA VERTEBRAL}

A coluna vertebral consiste de uma seqüência de ossos separados, irregulares que se estendem da região cervical as vértebras coccígeas. A coluna vertebral se divide em cinco regiões distintas: a cervical, que compreende as vértebras cervicais; a torácica, que compreende as vértebras torácicas; a lombar que compreende as vértebras lombares; as sacrais, que correspondem às vértebras sacrais e as coccígeas que correspondem às vértebras coccígeas.

\subsubsection{Coluna Vertebral}

Os contornos da coluna vertebral apresentam-se de forma diferente quanto ao padrão normal do animal em posição quadrupedal. A região cervical apresenta de uma forma convexa e posterior retilínea. O trajeto cervico-torácico apresenta-se ascendente ao contorno do dorso. As regiões tóraco-lombar apresentam-se retilíneas curvando-se ventralmente à região da pelve.

As vértebras cervicais são em número de sete. A primeira vértebra tem como característica um achatamento dorso ventral e um pequeno canal medular. A segunda possui em uma grande lâmina dorsal caracterizada pelo processo transverso como se fosse uma asa. A terceira vértebra apresenta um corpo bastante evidenciado com dois processos espinhosos bilaterais. Da quarta a sétima vértebra 
cervical os processos articulares são mais justapostos, os processos transverso permanecem inalterados seguindo a mesma forma até a sétima vértebra cervical, os processos espinhosos vão aumentando gradativamente e tendo um formato mais pontiagudo (Figura 01).

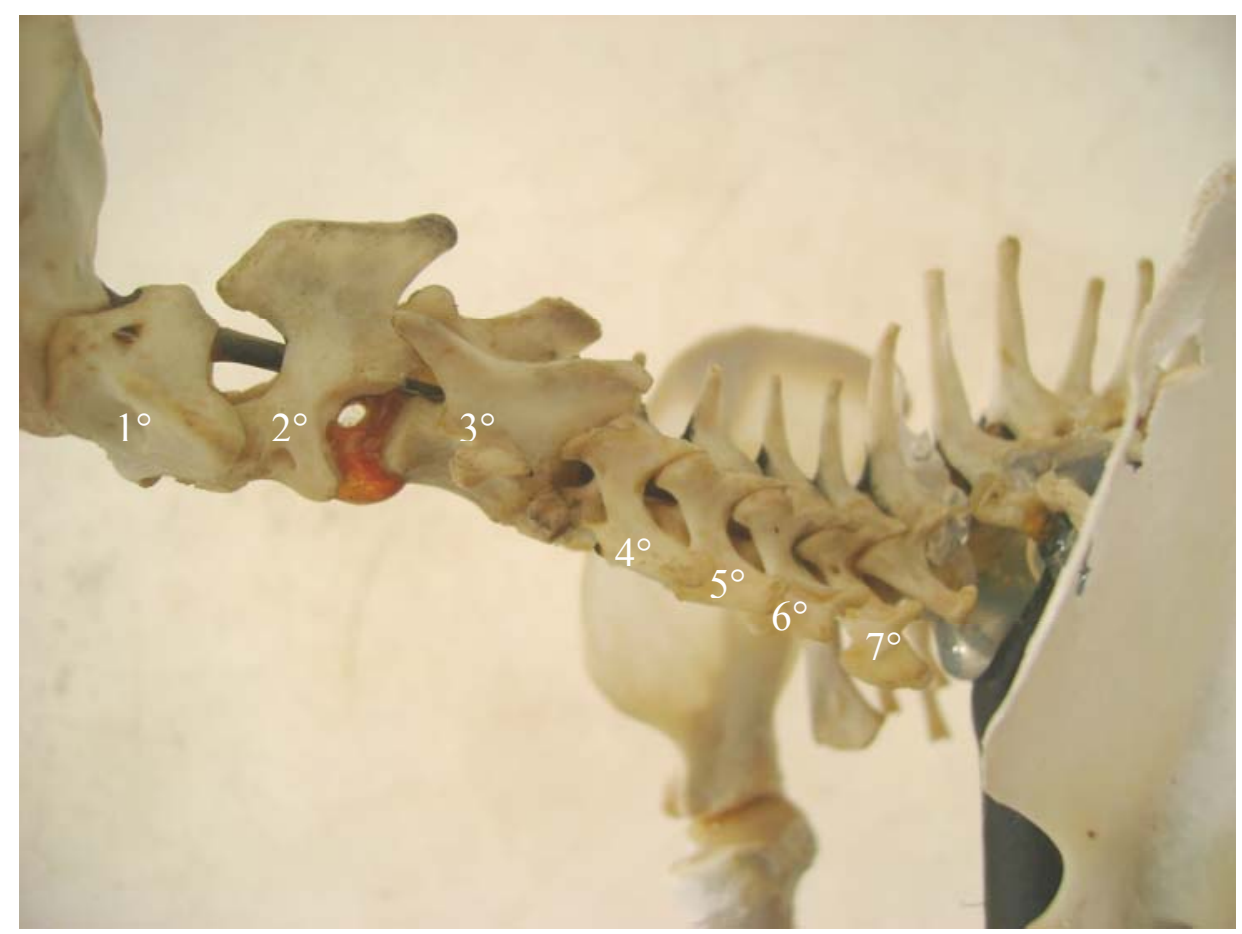

Figura 01 - Vista lateral de um esqueleto ósseo, referenciando as vértebras cervicais do quati (Nasua nasua)

As vértebras torácicas são em número de 15, com uma diferença no número de vértebras torácicas correlacionadas ao cão e gato, que correspondem a uma área pulmonar maior. Apresentam corpos vertebrais curtos em extremidades achatadas. Para cada corpo vertebral existe um processo articular com uma costela. Os processos transversos se localizam na região articular das costelas, sendo que nas três primeiras estes processos são bastante paralelos e nos restantes são direcionados cranialmente. Os processos espinhosos têm uma projeção bastante pronunciada em toda a sua extensão. Nos três primeiros processos há um aumento no seu tamanho e se apresentam bastante verticalizados, seguidos por uma pequena diminuição projetando-se caudalmente (Figura 02). 


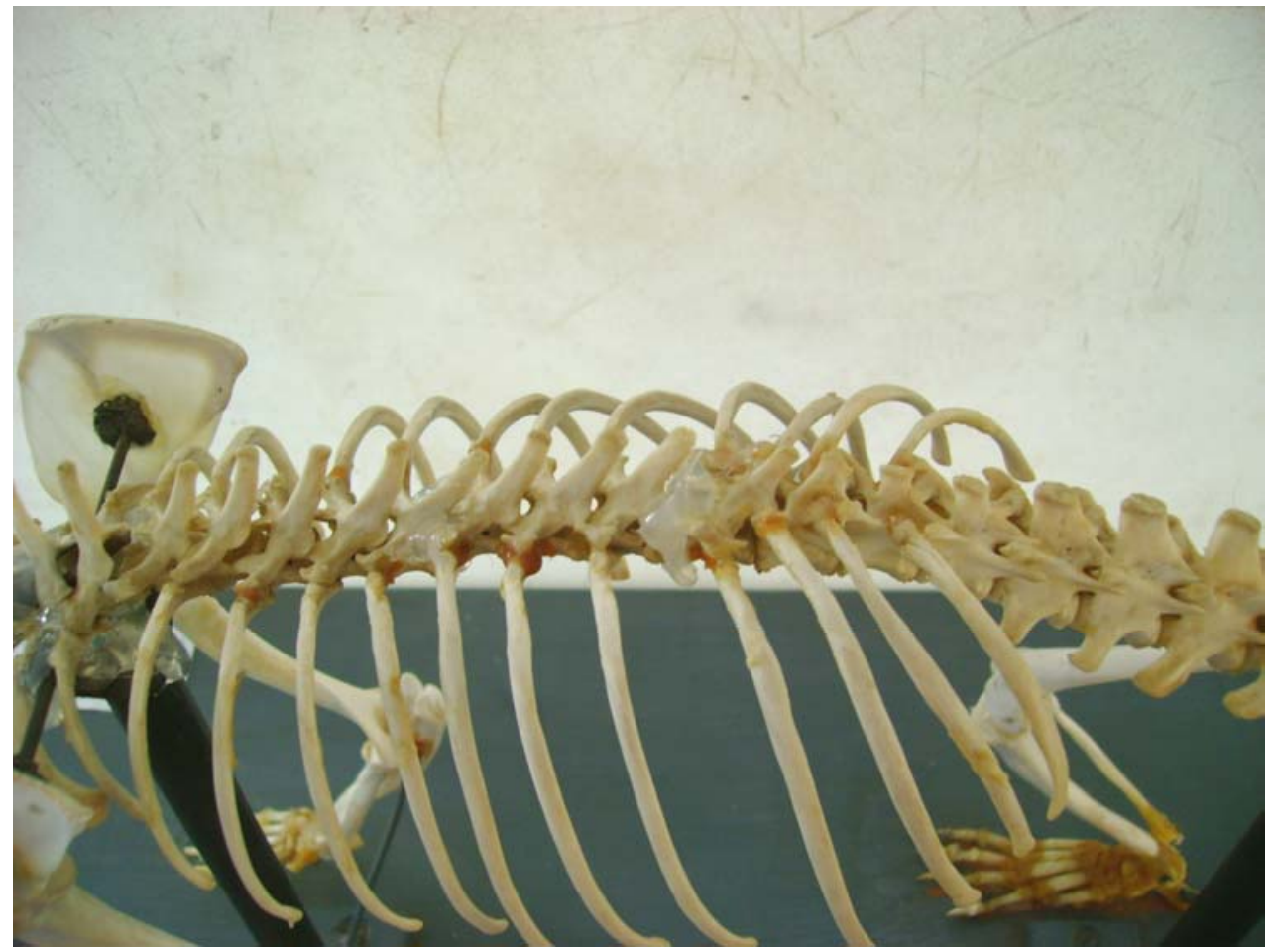

Figura 02 - Vista lateral de um esqueleto ósseo, referenciando as vértebras torácicas do quati (Nasua nasua)

As vértebras lombares variam de cinco a seis em seu número. Apresentam corpos vertebrais de tamanhos semelhantes e ausência de facetas costais. Os processos transversos apresentam projeções crânio-ventral e os processos espinhosos vão aumentando na sua altura, diminuindo a largura e se tornando mais proeminentes conforme o seu trajeto na coluna vertebral (Figura 03). 


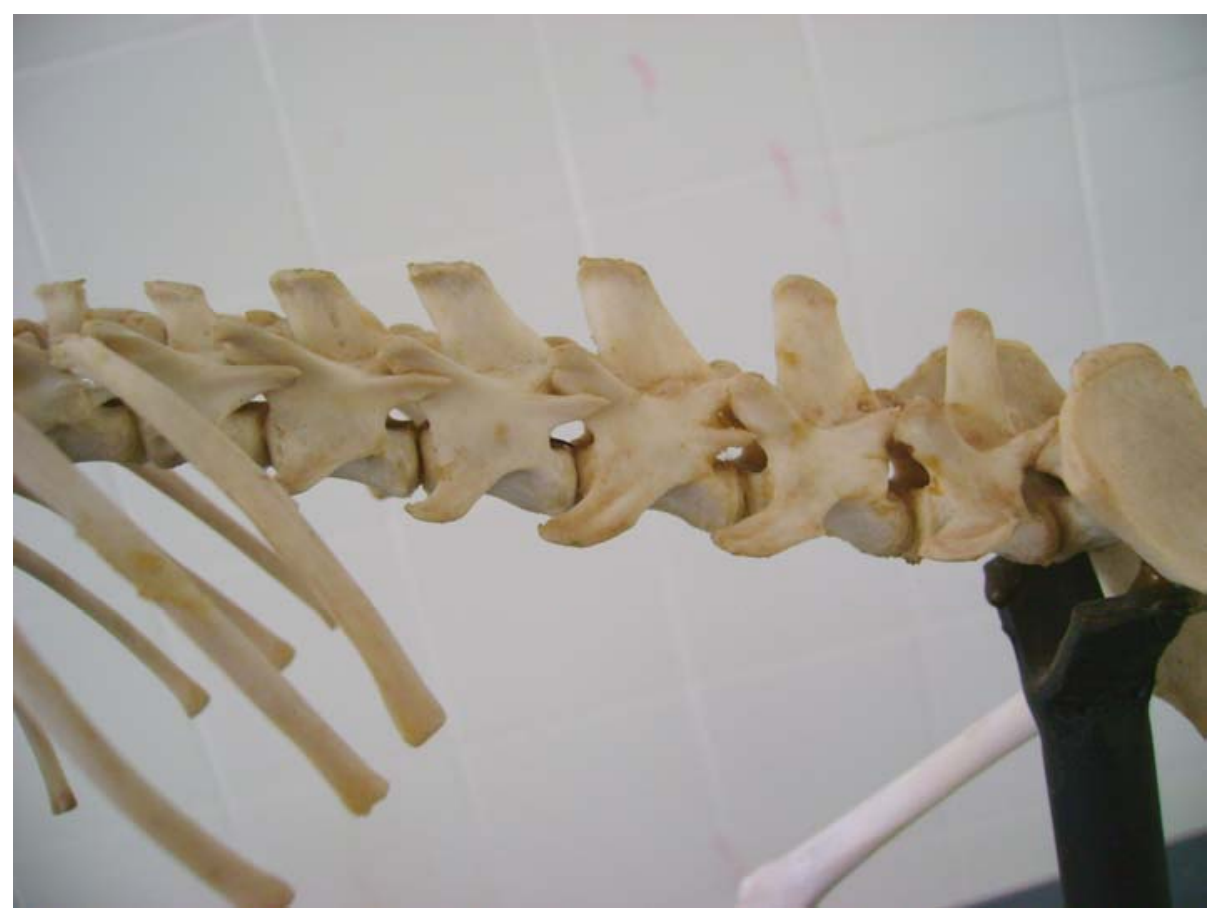

Figura 03 - Vista lateral de um esqueleto ósseo, referenciando as vértebras lombares do quati (Nasua nasua).

Caudalmente às vértebras lombares, localiza-se o sacro, decorrente da fusão de três vértebras sacrais caracterizada por uma forma achatada dorsalmente, além de comunicar diretamente com o osso íleo (Figura 04). Os processos espinhosos se apresentam bem menores que os da região lombar.

Cranial ao processo espinhoso da primeira vértebra sacral existe a presença de uma cartilagem em sentido cranial no local da punção, mas não impossibilita a realização da técnica. 


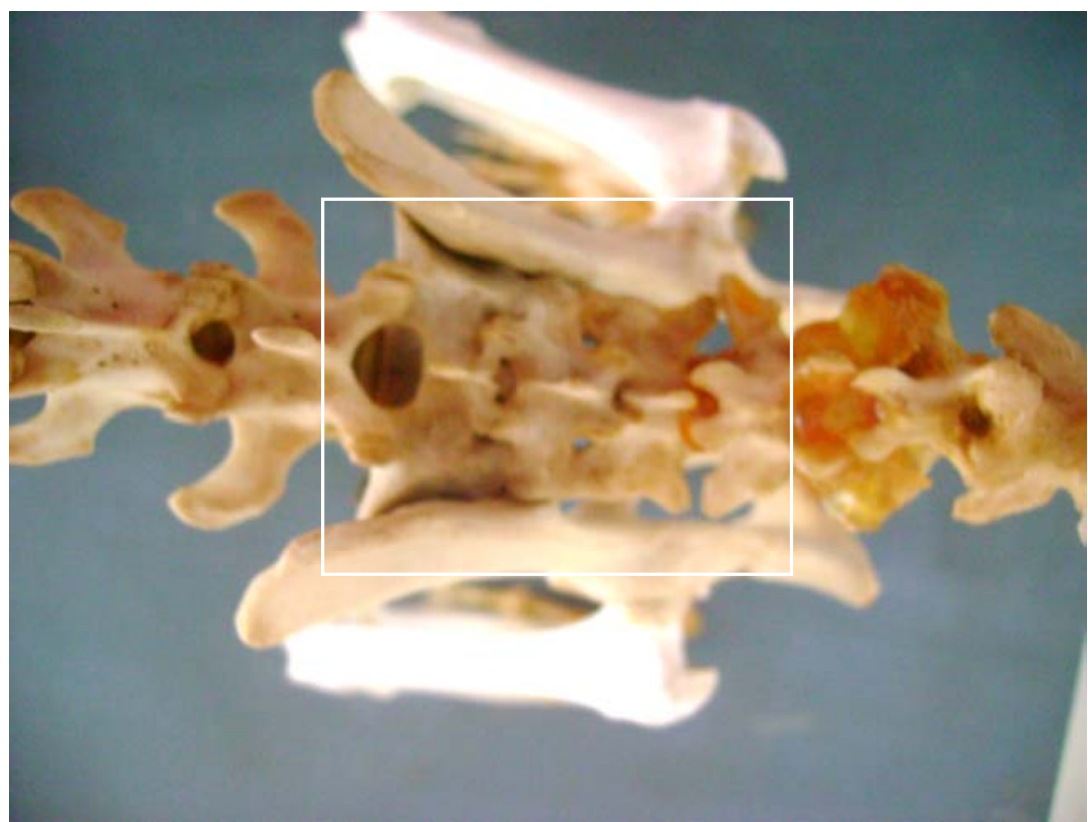

Figura 04 - Vista lateral de um esqueleto ósseo, referenciando o sacro do quati (Nasua nasua)

As vértebras coccígeas variam de 20 a 25 em número de vértebras. As primeiras vértebras coccígeas assemelham-se às vértebras lombares e tendem a seguir um padrão anatômico sem muitas particularidades (Figura 05).

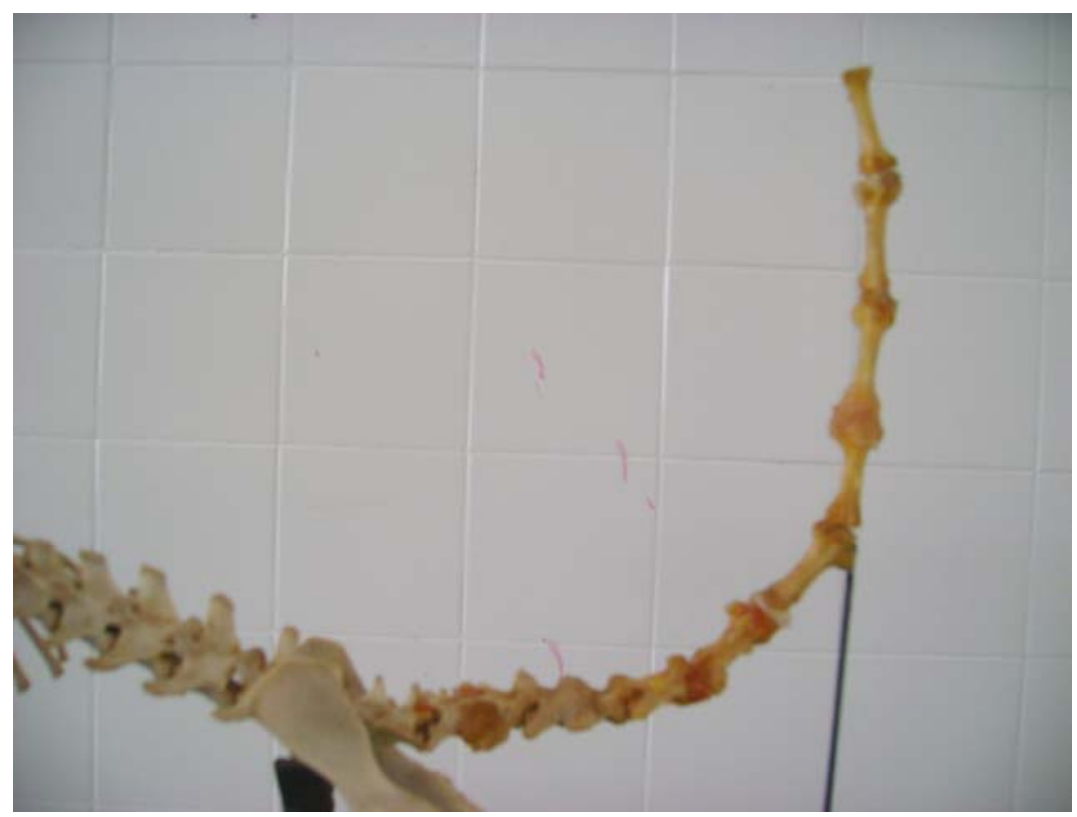

Figura 05 - Vista lateral de um esqueleto ósseo, referenciando as vértebras coccígeas do quati (Nasua nasua) 


\subsection{MEDULA ESPINHAL}

A medula espinhal apresenta-se como uma massa alongada, mais ou menos cilíndrica, com achatamento dorso-ventral, iniciando-se a partir da medula oblonga (cranial a primeira vértebra cervical) até o quinto ou sexto espaço intervertebral lombar (podendo ocorrer esta variação pelo número de vértebras). Existem duas dilatações que foram classificadas como intumescência cervical e lombar. A medula espinhal ao longo das vértebras lombares vai se afinalando-se à medida que termina as vértebras lombares e assume trajetos progressivamente mais longos dentro do canal dando origem a cauda eqüina.

\subsubsection{Intumescência cervical e Intumescência lombar}

A medula apresenta-se com uma forma cilíndrica, ligeiramente achatada dorso-ventral. Seu calibre varia devido às duas dilatações características: a intumescência cervical, formada entre o quarto e nono nervos espinhais (Figura 06) e a intumescência lombar formada entre $24^{\circ}$ e $27^{\circ}$ nervos espinhais (Figura 07).

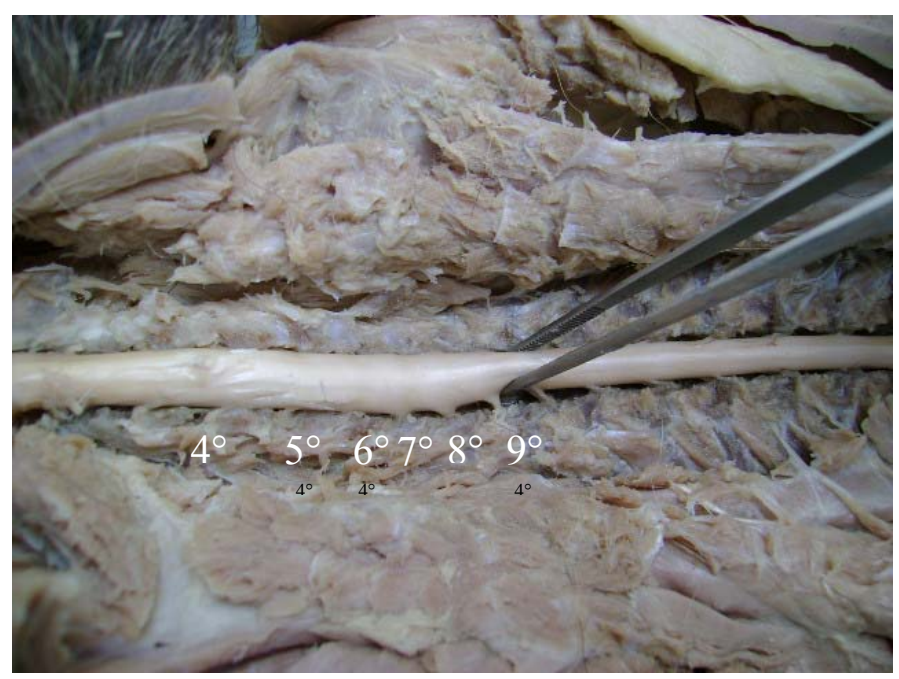

Figura 06 - Vista dorso lateral da medula espinhal, evidenciando a intumescência cervical do quati (Nasua nasua). 


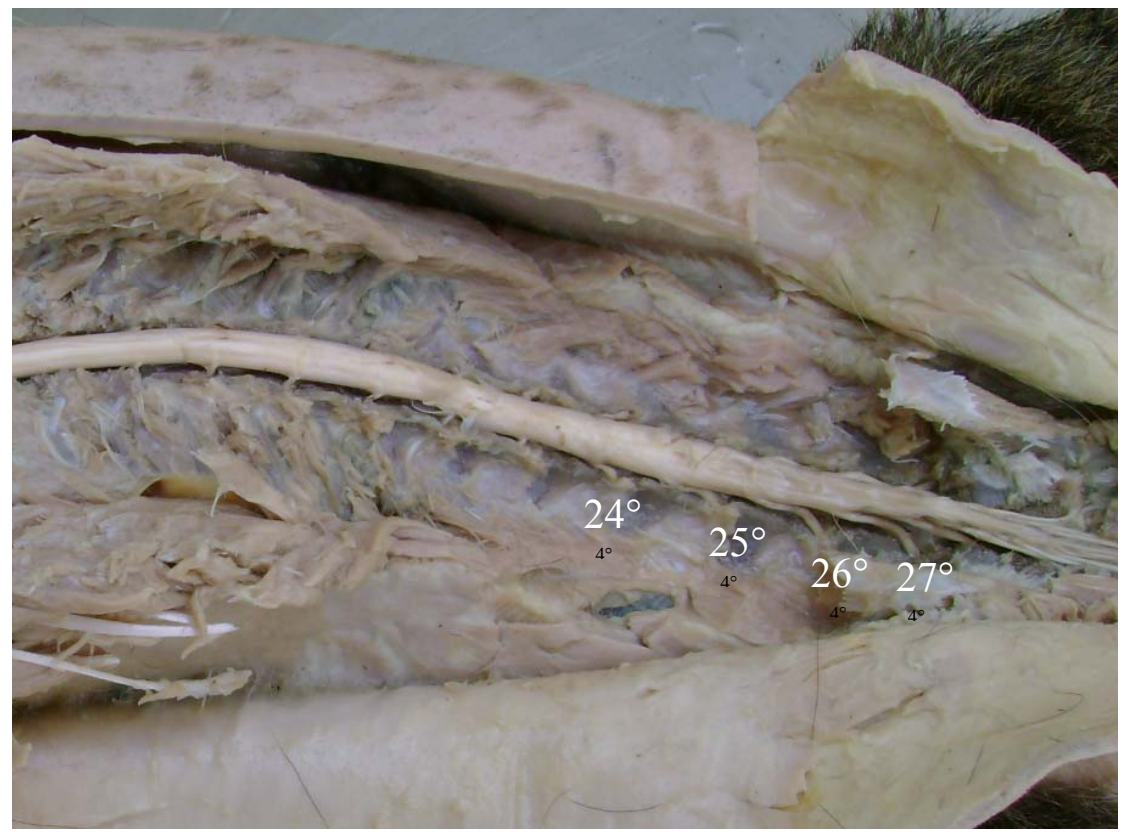

Figura 07 - Vista dorso lateral da medula espinhal, evidenciando a intumescência lombar do quati (Nasua nasua)

\subsubsection{Meninge Medular}

O que se pode notar é que existe uma membrana mais externa classificada com dura-máter onde se estende por toda a medula até o cone medular. As outras meninges como pia-máter e aracnóide, presentes em outras espécies domésticas, não foi visualizada mesoscopicamente porque os animais já estavam formolizados e está técnica de conservação fixa todo o tecido nervoso, alem do que, o liquido cefalorraquidiano logo após a morte tende a ser rapidamente absorvido (Figura 08). 


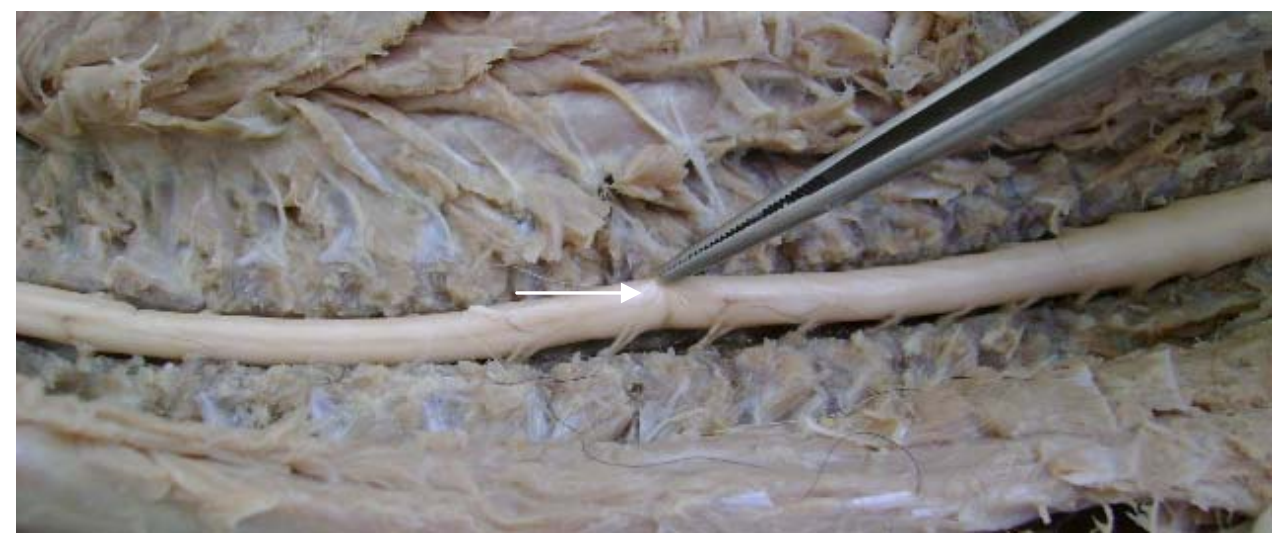

Figura 08 - Vista dorso lateral da medula espinhal, evidenciando a membrana dura-máter da medula espinhal no quati (Nasua nasua)

\subsubsection{Segmentação Medular}

Os nervos espinhais seguem um padrão ordenado e segmentar de 27 a 28 pares de nervos espinhais identificados até a cauda eqüina (sete cervicais, 15 torácicos, de cinco a seis lombares). Cada nervo é formado pela união de duas raízes, (Figura 9) a dorsal e a ventral, que após sua união se localiza o gânglio, uma intumescência, se repetindo da mesma maneira do lado oposto e cada raiz é composta por aproximadamente cinco radículas.

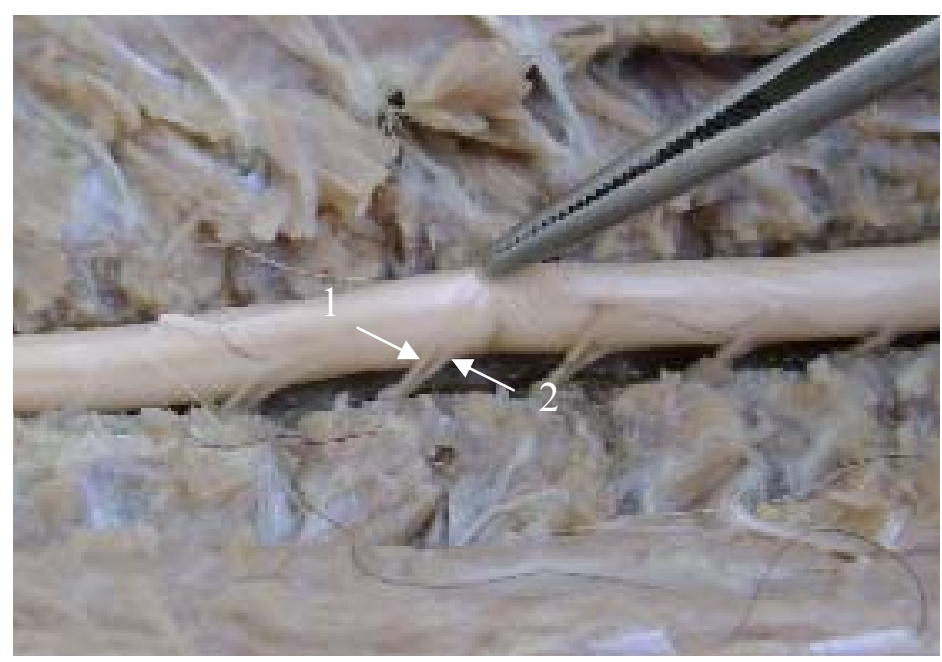

Figura 9 - Vista dorso lateral da medula espinhal, evidenciando com o número um a raiz dorsal e com o número dois a raiz ventral do quati (Nasua nasua) 


\subsection{PROCEDIMENTO ANESTÉSICO}

O procedimento anestésico desenvolveu-se em duas etapas: inicialmente foi realizada a contenção física, de forma que os animais pudessem participar da segunda etapa que foi estabelecer um protocolo anestésico para a correta contenção química para estes animais.

\subsubsection{Contenção Química}

Os animais apresentaram peso médio de 5,63 $\pm 0,68 \mathrm{~kg}$. Todos os animais receberam a dose de $20 \mathrm{mg} / \mathrm{kg}$ de cetamina-S associada a 0,5 $\mathrm{mg} \mathrm{kg}$ de midazolam, pela via intramuscular.

\subsubsection{Período de Latência, Hábil e de Recuperação}

O período de latência foi ao redor de 90 segundos (Tabela 1)em todos os animais tendo como resultado um tempo praticamente rápido e de fácil aplicação.

O período hábil foi de $68,12 \pm 2,58$ min (Tabela 01). Neste período foi avaliada a freqüência cardíaca e freqüência respiratória por meio do fonedoscópio a cada cinco minutos durante 60 minutos, tendo em média a freqüência cardíaca nos animais $218,70 \pm 30,70$ e a freqüência respiratória $24,47 \pm 3,10$.

A recuperação foi acompanhada de incoordenação motora que durou em média 20 minutos até a recuperação total (posição quadrupedal). Não se presenciou qualquer regurgitação, sialorréia e movimentos cataleptóides. 
Tabela 01 - Valores individuais, média e desvio-padrão do período hábil da contenção química com cetamina-S e midazolam nos quati (Nasua nasua).

\begin{tabular}{ccccccccccc}
\hline Animais & $\mathbf{1}$ & $\mathbf{2}$ & $\mathbf{3}$ & $\mathbf{4}$ & $\mathbf{5}$ & $\mathbf{6}$ & $\mathbf{7}$ & $\mathbf{8}$ & Média & DP \\
\hline $\begin{array}{c}\text { Tempo } \\
(\mathbf{m i n})\end{array}$ & 65 & 70 & 65 & 65 & 70 & 70 & 70 & 70 & 68,12 & 2,58 \\
\hline
\end{tabular}

\subsubsection{Freqüência cardíaca e respiratória.}

Os valores obtidos não apresentaram diferença no decorrer da avaliação e estão apresentados nas tabelas 02 e 03.

Tabela 02. Valores individuais, médias e respectivos desvios-padrão da freqüência cardíaca (batimentos por minuto) dos quatis (Nasua nasua) anestesiados com cetamina-S e midazolam.

\begin{tabular}{ccccccc}
\hline \multirow{2}{*}{ Animais } & \multicolumn{7}{c}{ Momentos (min) } \\
\cline { 2 - 7 } & 5 & 10 & 20 & 30 & 40 & 60 \\
\hline 1 & 280 & 240 & 240 & 220 & 220 & 220 \\
2 & 260 & 260 & 260 & 260 & 260 & 260 \\
3 & 260 & 260 & 260 & 240 & 260 & 260 \\
4 & 210 & 210 & 220 & 220 & 240 & 240 \\
5 & 200 & 200 & 200 & 200 & 220 & 240 \\
6 & 200 & 200 & 200 & 200 & 220 & 240 \\
7 & 220 & 220 & 220 & 180 & 180 & 180 \\
8 & 180 & 180 & 180 & 140 & 140 & 160 \\
\hline Média & 202 & 198 & 200 & 188 & 198 & 206 \\
\hline DP & 81 & 76 & 73 & 69 & 70 & 68 \\
\hline
\end{tabular}


Tabela 03. Valores individuais, médias e respectivos desvios-padrão da freqüência respiratória (movimentos respiratórios por minuto) dos quatis (Nasua nasua) anestesiados com cetamina-S e midazolam

\begin{tabular}{ccccccc}
\hline \multirow{2}{*}{ Animais } & \multicolumn{7}{c}{ Momentos (min) } \\
\cline { 2 - 6 } & 5 & 10 & 20 & 30 & 40 & 60 \\
\hline 1 & 24 & 26 & 26 & 24 & 22 & 20 \\
2 & 22 & 22 & 26 & 24 & 26 & 26 \\
3 & 26 & 26 & 24 & 26 & 26 & 26 \\
4 & 20 & 22 & 20 & 22 & 24 & 24 \\
5 & 20 & 20 & 20 & 20 & 24 & 24 \\
6 & 20 & 20 & 20 & 20 & 24 & 22 \\
7 & 26 & 28 & 32 & 28 & 32 & 32 \\
8 & 24 & 26 & 26 & 26 & 28 & 26 \\
\hline Média & 21 & 22 & 24 & 24 & 27 & 28 \\
\hline DP & 6,4 & 5,4 & 4,2 & 3,4 & 5,6 & 9,0 \\
\hline
\end{tabular}

\subsubsection{Relaxamento Muscular}

O relaxamento muscular, avaliado por meio da resistência à flexão dos membros, foi satisfatório, pois os animais não apresentaram nenhum movimento involuntário, possibilitando o posicionamento na avaliação clínica, no momento da avaliação radiológica, bem como durante as manipulações para avaliação do tegumento, sem demonstrar reflexos.

A resistência à abertura da boca foi avaliada tendo como principal resultado a avaliação da cavidade oral.

A observação da atividade muscular não induzida teve como principal avaliação o animal posicionado na mesa com ou sem manipulação onde não se observou nem fasciculações, nem movimentos espásticos em toda a sua musculatura. 


\subsubsection{Analgesia}

A analgesia obtida durante a contenção química foi moderada em todos os animais. Os animais não apresentaram desconforto na canulação venosa, na punção da veia jugular para coleta de sangue, durante a aplicação de antibiótico e nem no momento de sondagem vesical. Com a contenção química pode se notar que os reflexos protetores, o palpebral, o anal e o interdigital, se preservaram.

\subsection{ANESTESIA ESPINHAL}

Esta técnica possibilitou a determinação da posição exata da punção, que se referencia com uma angulação de 90 graus a 110 graus (Figura 10), na região lombossacro (espaço epidural), não apresentando mais medula espinhal e sim a presença da cauda eqüina.

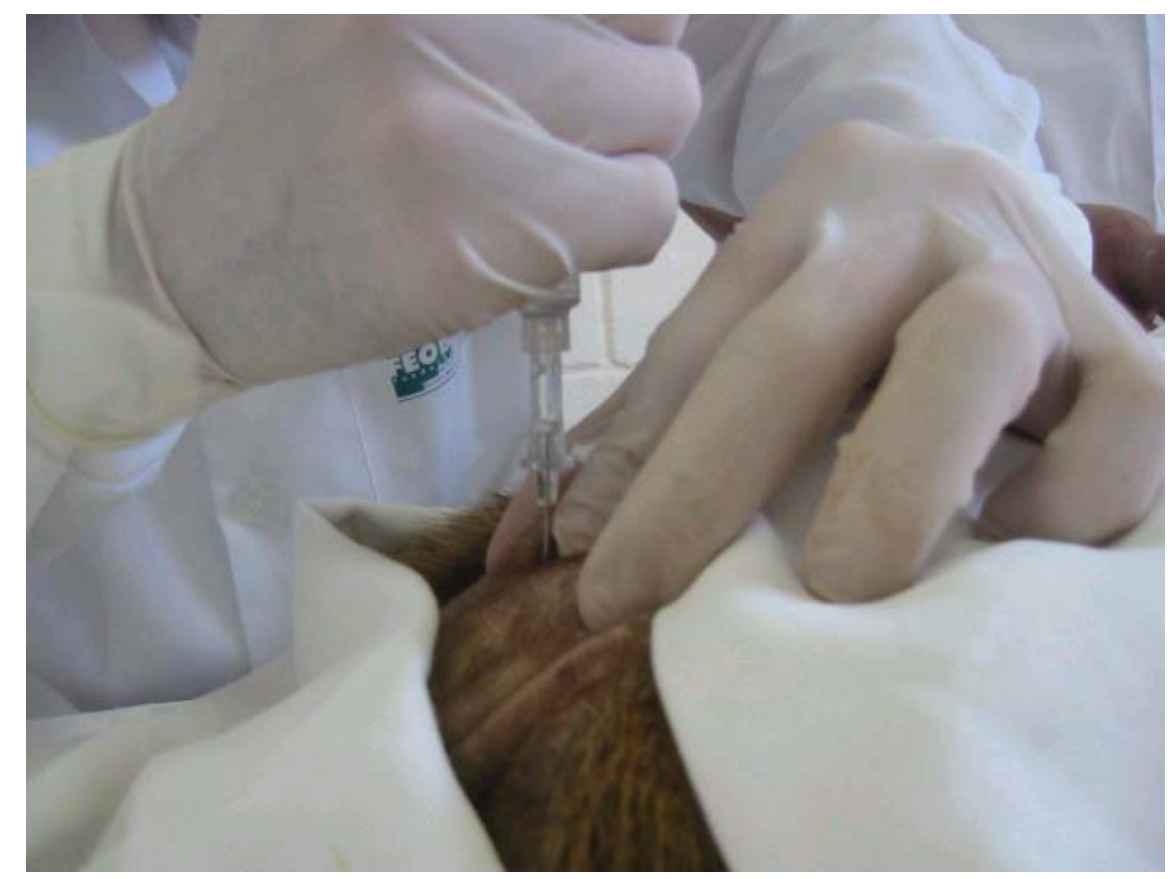

Figura 10 - Posição verticalizada em um ângulo de 90 graus, referenciando a posição da punção no espaço lombosacro. 


\subsubsection{Período de Latência}

O período de latência teve como avaliação a região pélvica e a região perineal. Evidenciou-se que o período de latência para a anestesia da região pélvica ocorreu em cinco minutos. A respeito da região perineal também foi verificado o mesmo tempo de cinco minutos nos mesmos animais, uma vez que esta região está intimamente correlacionada com a anterior.

\subsubsection{Período Hábil, Relaxamento muscular e Analgesia}

O período hábil anestésico foi determinado por meio da avaliação clínica do relaxamento muscular e estímulo ao reflexo anal, tendo como avaliação o relaxamento das musculaturas dos membros pélvicos e o esfíncter anal nos quatis, observado em um período de 40 minutos, onde se pode ressaltar o relaxamento do esfíncter anal e relaxamento da cauda. Quanto à analgesia, que foi verificada por meio de estímulo doloroso pelo pinçamento interdigital no membro pélvico, onde não ocorreu nenhum reflexo de flexão ou fasciculação muscular, por aproximadamente 40 minutos. 
GREGORES, G. B. 


\section{DISCUSSÃO}

Para elucidar melhor este capitulo, foram determinadas subdivisões que compreenderam respectivamente os estudos referentes aos aspectos morfológicos (anatomia), a contenção química e a anestesia espinhal.

\subsection{ASPECTOS MORFOLÓGICOS}

Os estudos referentes à anatomia, contenção química e anestesia espinhal em quatis são muito escassos e de pouca especificidade. $O$ que se pode notar referente às pesquisas destes animais é que existem diversos trabalhos relacionados ao estudo comportamental em vida livre, trabalhos referentes a doenças infecciosas e trabalhos referentes a procedimentos ventilatórios (mas em outra família) (BEISIEGEL, 2001; BOGGS; IRVIN, 1992; GRANT et al., 1976). No que diz respeito à coluna vertebral, medula espinhal e anestesia espinhal, esta pesquisa se torna pioneira, pois não há referência na literatura pesquisada sobre este assunto nestes animais. Em virtude deste aspecto, salienta-se que toda a parte das discussões e observações é realizada com base nos dados em cães e gatos.

\subsubsection{Morfologia da Coluna Vertebral}

A coluna vertebral do quati (Nasua nasua) apresentou diferença na sua formação, sem muitas peculiaridades, das quais é possível destacar: a presença das duas primeiras vértebras cervicais, classificadas no cão e gato como sendo chamadas de atlas e axis citadas por Dyce, Sack, Wensiwg (2004), seguem a mesma forma na espécie estudada, porém com uma particularidade maior no atlas, que possui um pequeno canal medular pouca região de articulação com o axis, 
proporcionando uma grande flexibilidade articular desta região, observada no animal. O número de vértebras corresponde ao do cão e gato.

As vértebras torácicas também apresentam aspectos que necessitam ser comentados. Dyce, Sack, Wensiwg (2004) descreve a presença de 13 vértebras torácicas no cão. Este achado se difere em número do encontrado no quati (Nasua nasua), onde se pode confirmar a presença de 15 vértebras torácicas tendo em cada uma dela o seu processo articular com a costela.

A descrição realizada por Dyce, Sack, Wensiwg (2004), diz que os animais (cão e gato) possuem seis vértebras lombares, podendo ocorrer uma variação em número reduzindo para cinco. Da mesma forma, nos animais estudados observou-se mais freqüentemente a ocorrência de seis vértebras lombares, mas podendo haver cinco vértebras lombares, eventualmente.

Nas vértebras sacrais foi encontrada uma particularidade observada pelo autor sobre a cartilagem cranial ao primeiro processo espinhoso da primeira vértebra sacral, diferença significativa em comparação com os animais domésticos (cão e gato) onde não se encontrou descrição por outros autores como Dyce, Sack, Wensiwg (2004). Esta cartilagem foi bem observada uma vez que nesta região é que foi realizada a punção para anestesia espinhal. Sobre os processos espinhosos, processos transversos e os processos articulares não notaram diferença significativa.

Vale ressaltar também que as vértebras coccígeas (caudais) não mostraram diferença na sua forma e sim em números que podem variar de 20 a 25 vértebras, lembrando que Dyce, Sack, Wensiwg (2004) comentaram que podem variar de 20 a 23 vértebras no cão e no gato.

\subsection{SISTEMA NERVOSO}

Da mesma maneira citada por Cunningham (2004), a medula espinhal fica enclausurada no canal vertebral, formada por uma série de ossos protetores (as 
vértebras cervicais, torácicas e lombares) onde estão as raízes espinhais dorsal e ventral que pertencem ao sistema nervoso periférico.

\subsubsection{Medula Espinhal}

Como já descrito nos resultados a medula espinhal é uma estrutura alongada, mais ou menos cilíndrica, mas com algum achatamento dorso-ventral e determinadas variações regionais de forma e dimensões, inicia-se a partir da medula oblonga até o quinto ou sexto espaço intervertebral lombar. Estas variações também ocorrem em cães e são chamadas de intumescências. As intumescências citadas por Dellmann e Mcclure (1975) incluem a intumescência cervical que inicia no quinto segmento da medula espinhal cervical até o segundo segmento espinhal da medula torácica. $\mathrm{O}$ que se pode notar que nos quatis se inicia no quarto e termina no nono nervo espinhal (quarto segmento da medula espinhal cervical ao segundo segmento da medula torácica).

A intumescência lombar no cão ocorre no início do quarto segmento lombar e termina no segundo segmento sacral. No quati o que se pode afirmar é que a intumescência lombar se inicia entre o $24^{\circ}$ e o $27^{\circ}$ nervos espinhais compreendendo entre a segunda e quinta vértebra lombar, localizando-se mais cranial em relação ao cão. Na região sacral foi verificada a presença da cauda eqüina.

Sobre as meninges citado por Dellmann e Mcclure (1975), no cão o filamento da dura-máter espinhal está inserido no periósteo do canal espinhal da sétima ou oitava vértebras caudais. $\mathrm{O}$ que se pode afirmar é que na região onde se localizou o espaço denominado lombo-sacro (espaço de punção da anestesia espinhal) existe uma estrutura inserida no periósteo com consistência fibroso bem característico ao ligamento intervertebral. Foi verificada a presença de uma meninge classificada como dura-máter, que se estende por toda a medula espinhal até o cone medular, sendo a mais visível, não podendo afirmar a presença de outras estruturas através da mesoscopia como aracnóide e pia-máter. 
Segundo o Dyce, Sack, Wensiwg (2004) A distribuição dos nervos espinhais segue o mesmo trajeto encontrado nas outras espécies (cão e gato). $\mathrm{O}$ desvio relativo na posição (ascensus medullae) leva os segmentos da medula cranialmente com relação às suas posições originais dentro das vértebras das mesmas designações numéricas. $O$ desvio dos segmentos mais caudais é mais pronunciado e explicam o arranjo peculiar de nervos espinhais associados. Os nervos apresentam raiz dorsal e ventral que quando se juntam formam uma estrutura esférica chamando-a de gânglio. Também foi observada a presença de dendritos (pequenas ramificações da medula espinhal que dão origem a um nervo espinhal).

\subsection{PROCEDIMENTO ANESTÉSICO}

A associação cetamina-S e midazolam foi de simples aplicação e gerou facilidade na manipulação, uma vez que não se sabia a respeito do comportamento fisiológico da espécie animal estudada. Evans (2002) estabeleceu diversos protocolos para a Família Procyonidae, utilizando 20 animais do gênero (Nasua sp.) notou uma boa imobilização, analgesia adequada atingindo até 10 minutos de duração, $17 \%$ deles tiveram rigidez muscular, convulsões tônico-clônicas quando se utilizou a cetamina. Notou-se que a associação da cetamina-S e midazolam não desencadearam reações indesejáveis tais como hipertonia muscular, excitação ou na recuperação.

Hanson et al. (2000) estudaram, em seis quatis (Nasua narica), a resposta vascular pulmonar na hipóxia crônica sedando-os com a cetamina na dose de 22 $\mathrm{mg} / \mathrm{kg}$, e posteriormente anestesiando-os com pentobarbital sódico na dose de 12 $\mathrm{mg} / \mathrm{kg}$ e brometo de pancurônio para o relaxamento muscular completo. $\mathrm{O}$ autor não apresenta resultados isolados quanto à anestesia, não permitindo, assim, maiores comparações com o presente estudo.

Por se tratar de animal não doméstico, há necessidade da contenção física seguida da química sem avaliação precisa dos parâmetros cardiorrespiratórios. Desta forma, não foi possível a realização da avaliação pré-anestésica, e de acordo 
com os dados registrados no decorrer da contenção química, não se observou diferença nas freqüências cardíaca e respiratória. A aplicação de cetamina, através de via intravenosa em cães, sem medicação pré-anestésica, é caracterizada por aumento da pressão arterial média, da freqüência cardíaca e do débito cardíaco. Os efeitos cardio-estimulatórios podem ser desencadeados por vários mecanismos fisiológicos, incluindo efeitos simpatomiméticos mediados por estruturas no SNC, inibição da captação intra e extraneural de catecolaminas e inibição do componente vagal do reflexo em barorreceptores. O uso de midazolam concomitantemente é capaz de bloquear os efeitos cardio-estimulatórios da quetamina, com exceção do aumento na freqüência cardíaca (JACOBSON; HARTSFIELD, 1993). Desta forma, de acordo com a literatura consultada, é provável que o agente dissociativo tenha desencadeado este incremento, mas não há condição de confirmação.

\subsection{ANESTESIA ESPINHAL}

Como descrito por Cortopassi, Fantoni e Bernardi (2002), os anestésicos locais como a lidocaína bloqueiam reversivelmente a condução nervosa, quando aplicados no tecido nervoso em concentração apropriada, não provocando danos estruturais as células nervosas. Este efeito reversível foi verificado na espécie estudada. Nos animais estudados que foram submetidos à anestesia epidural se notou um bloqueio local onde o anestésico espalhou-se na área paravertebral, através do forame paravertebral e bloqueou os ramos nervosos distais às bainhas durais (de cada forame), resultando em bloqueio paravertebral múltiplo, como já descrito por Torske e Dyson (2000).

A anestesia epidural promove analgesia ou anestesia apenas para a porção caudal do corpo, o movimento da parte cranial pode ser um problema relata Haskins (1992). Isto se pode confirmar através da anestesia epidural nos quatis, onde se notou toda a analgesia em membros pélvicos e membros torácicos totalmente sensíveis ao estímulo doloroso. 
Schimidt et al. (1993) citam que as vantagens do bloqueio epidural são: a falta de depressão central; funções cardiorrespiratórias preservadas e analgesia e relaxamento muscular ideais, sendo indicada para pacientes de alto risco. Isto ficou bem demonstrado no presente estudo, onde os parâmetros fisiológicos foram mantidos e o relaxamento muscular foi bastante adequado.

Cabe ressaltar, como descrito por Intelizano et al. (2002), que a anestesia epidural tem sido erroneamente considerada uma anestesia livre de efeitos deletérios e complicações. Seus efeitos cardiovasculares, por exemplo, são facilmente compensados em um paciente hígido, porém podem ser irreversíveis em pacientes com alterações. Dessa forma é necessária uma avaliação cuidadosa do quadro clinico antes de se optar pela anestesia epidural. No presente estudo, as variáveis avaliadas, como freqüência cardíaca e freqüência respiratória, não apresentaram variações no decorrer do procedimento sugerindo estabilidade, sem depressões evidentes.

Campoy (2004) descreveu em cães a técnica de anestesia epidural utilizando um cateter $22 \mathrm{G}$, no espaço lombo-sacro após a sétima vértebra lombar com a inclinação de $90^{\circ}$, onde utilizou a lidocaína na dose de $4,0 \mathrm{mg} / \mathrm{kg}$, tendo como resultado em tempo de latência de cinco minutos, uma duração de 45 a 90 minutos. Estes dados vêm ao encontro do presente estudo em vários aspectos. Inicialmente, empregou-se o mesmo tipo de cateter para a punção epidural. O espaço foi considerado o mesmo uma vez que nos quatis este espaço lombo-sacro se localiza entre a quinta ou sexta vértebra lombar com a primeira vértebra sacral. Quanto ao fármaco empregado, em ambos o estudo utilizou-se a lidocaína na dose de 4,0 $\mathrm{mg} / \mathrm{kg}$ com tempo de latência semelhante, de $5 \mathrm{~min}$. O que se notou de diferente foi o período hábil do presente fármaco que nos quatis foi de $40 \mathrm{~min}$. A duração do efeito da lidocaína varia de 60 a 120 min segundo a literatura pesquisada (SKARDA, 1996). Tal diferença deve-se, provavelmente, ao espaço epidural bastante reduzido, o qual proporcionaria rápida distribuição do anestésico para os nervos espinhais, ramos nervosos, gânglios e difusão na dura-máter. Outra especulação possível de ser realizada é quanto à dose empregada. Uma vez que não se conhece a farmacocinética da lidocaína na espécie em questão, poderia se considerar que a 
dose administrada foi suficiente para promover a anestesia por período mais curto do que é observado em outras espécies.

Vale ressaltar que logo após o período de latência de cinco minutos da aplicação da anestesia epidural, observou-se relaxamento da musculatura do esfíncter anal externo, seguido de relaxamento da cauda concordando com o raciocínio de Skarda (1996). Entretanto, o reflexo interdigital se ausentou após cinco minutos de latência nos quatis, diferentemente do que é relatado nos cães, que é um período de 10 a 15 minutos. Novamente, partindo da suposição de que o espaço lombossacro no quati é mais reduzido, haveria maior e mais rápida distribuição do anestésico local.

Os animais apresentaram uma recuperação isenta de fenômenos excitatórios, observando-se, apenas, incoordenação motora. Tal fato comprova os achados experimentais obtidos em outras espécies (humanos e caninos), onde a mistura racêmica, por possuir o isômero $\mathrm{R}(-)$, apresenta maiores respostas deletérias, tais como agitação e comportamento agressivo (WHITE; SCHUTTLER; SHAFER, 1985).

Finalizando, vale relatar que a dificuldade na obtenção desta espécie animal para o presente estudo imposta por organizações não governamentais, ambientalistas, IBAMA, Governo Federal entre outros, torna mais complexo um estudo morfo-fisiológico. Esses obstáculos da busca pelo conhecimento fazem com que as informações desta e de dezenas de outras espécies sejam escassas e incompletas, causando indignação e ao mesmo tempo um despertar do interesse dos pesquisadores em contribuir para a ciência.

Dessa forma, torna-se difícil este estudo pela falta de base de sustentação de informações de demais pesquisas. No entanto, objetiva-se contribuir para o estudo da espécie.

A adequação de protocolos anestésicos para a espécie em estudo propiciará mais subsídios para sua clínica e preservação, uma vez que, os quatis (Nasua nasua) poderão ser manipulados de forma mais segura e cautelosa. Acredita-se que os resultados deste estudo colaborarão para anestesiologia de mais um animal da fauna silvestre brasileira. 
7 CONCLUSÕES 


\section{CONCLUSÕES}

A partir dos resultados obtidos pode se concluir:

1. As vértebras da coluna do quati (Nasua nasua) apresentam-se como uma estrutura única tendo suas particularidades em cada vértebra ao longo do seu trajeto.

2. A medula espinhal se apresenta como uma massa esbranquiçada, alongada e cilíndrica, presente dentro do canal vertebral até o quinto ou sexto espaço intervertebral lombar, onde se nota a presença da cauda eqüina.

3. A associação da contenção química com cetamina-S e midazolam e a anestesia espinhal, empregando lidocaína, demonstrou ser técnica segura, promovendo bom relaxamento muscular e analgesia adequada para procedimentos cirúrgicos na região pélvica. 


\section{REFERÊNCIAS}

BEISIEGEL, B. M. Notes on the coati, Nasua nasua (Carnívora: Procyonidae) in na Atlantic Forest area. Brazilian Journal of Biology, v. 61 n. 4: p. 689-692, 2001.

BOGGS, D. F.; IRVIN C. G. Respiratory mechanics of the coatimundi and woodchuck. Respiration Physiology, v. 89, p. 147-155, 1992.

CAMPOY, L. Epidural and spinal anaesthesia in the dog. In Practice, v. 26 p. 262269, 2004.

CARVALHO, R. C. Topografia vértebro-medular e Anestesia espinhal em Joboti das "Patas Vermelhas" Geochelone carbonaria (SPIX, 1824). 2004. 126 f. Dissertação (Mestrado em Ciências) - Faculdade de Medicina Veterinária e Zootecnia, Universidade de São Paulo, São Paulo, 2004.

CORTOPASSI, S. R. G.; FANTONI, D. T. Medicação pré-anestésica. In: Anestesiologia em Cães e Gatos. São Paulo: Roca, 2002. cap.13, p.151-158.

CORTOPASSI, S. R. G.; FANTONI, D. T.; BERNARDI, M. M. Anestésicos Locais. In: SPINOSA, H. S.; GORNIAK, S. L.; BERNARDI, M.M. Farmacologia aplicada à medicina veterinária. 3. ed. Rio de Janeiro: Guanabara Koogan, 2002. p. 129-136.

CUNNINGHAM, J. G. Tratado de fisiologia veterinária. 3. ed. Rio de Janeiro Guanabara Koogan, 2004. 579 p. 
DELLMAN, H. D.; MCCLURE, R. C. Sistema Nervoso Central dos carnívoros In: GETTY, R. Anatomia dos animais domésticos, 5. ed. Rio de Janeiro: Guanabara Koogan 1975. v. 2.

DINIZ, L. S. M. Imobilização química em animais silvestres. In: SPINOSA, H. S.; GORNIAK, S. L.; BERNARDI, M. M. Farmacologia Aplicada à medicina veterinária. 3. ed. Rio de Janeiro: Guanabara Koogan, 2002. p. 174.

DYCE, K. M.; SACK, W. O.; WENSIWG, C. J. G. Tratado de anatomia veterinária. 3. ed: Rio de Janeiro, Guanabara Koogan, 2004. 813 p.

EVANS, R. H. Raccons and Relatives (Carnívora Procyonidae). International veterinary information, Ithaca, New York. Zoological Restring and Anesthesia, CA, USA, 2002. [12] $p$.

FANTONI, D. T.; CORTOPASSI, S. R. G.; BERNARDI, M. M. Anestésicos intravenosos e outros parenterais. In: SPINOSA, H. S.; GORNIAK, S. L.; BERNARDI, M. M. Farmacologia aplicada à medicina veterinária. 3. ed. Rio de Janeiro: Guanabara Koogan, 2002. p. 117-128.

FLETCHER, T. F. Spinal cord and meninges. In: EVANS, H. E. Anatomy of the dog. 3. ed., Philadelphia: Pennsylvania: W.B. Saunders, 1993. v. 16, p. 800-806

GRANT, B. J. B.; DAVIES, E. E.; HAZEL, A. J.; HUGHES, J. M. B. Local regulation of pulmonary blood flow and ventilation-perfusion ratios in the coatimundi. Journal of Applied Physiology, v. 89, n. 2, p. 216-228, 1976. 
GREENE, N. M. Perspectives in spinal anesthesia. Reginal Anesthesia, v.7, n. 55, 1982.

HANSON, W. L.; BOGGS, D. F; KAY, M.; HOFMEISTER S. E.; OKADA O.; WAGNER, W. W. Pulmonary vascular response of the coati to chronic hypoxia. Journal of Applied Physiology. v. 88, p. 981-986, 2000.

HARLEY, T. J.; GIDLEY, J. T. Pharmacological comparison of R (+), S (-) and racemic secobarbital in mice. European Journal of Pharmacology. v. 9, p. 358, 1970.

HASKINS, S. Problems and precautions when using epidural analgesia for surgery. Veterinary Clinics of North America: Small Animal Practice, v. 22, n. 2, p. 420421, 1992.

HELLYER, P. W.; FREEMAN, L. C.; HUBBELL, J. A. Induction of anesthesia with diazepam-ketamine and midazolam-ketamine in greyhounds. Veterinary Surgery, $v$. 20, n. 2, p. 143-147, 1991.

INTELIZANO, T. R; SANTOS, P. R.; FUTEMA, F.; OTUSUKI, D. A.; ALMEIDA, T.A. Técnicas de Anestesia local - Anestesia epidural. In: FANTONI, D. T.; CORTOPASSI, S. R. G. Anestesia em cães e gatos. Roca: São Paulo, 2002. p. 19, 206-208.

JACOBSON, J.D.; HARTSFIELD, S.M. Cardiovascular effects of intravenous bolus administration and infusion of ketamine-midazolam in isoflurane-anesthetized dogs. American Journal of Veterinary Research, v.54, n.10, p.1715-20, 1993. the dog. 3. ed. W. B. Saunders Philadelphia: Pennsylvania, 1993. v. 16, p. 829-893. 
MAILHAC, J. M.; CHAFFAUX, S.; ALVAREZ, R. Anesthésie epidurale chez lê chien. Recueil de Medicine Veterinaire. V. 156, n. 4, p. 277-282, 1980.

MCCLEARN D. Anatomy of Raccoon (Procyon lotor) and Coati (Nasua narica and N. nasua) Forearm and Leg Muscles: Relations Between fiber lengh, moment-arm length, and Joint-Angle excursion. Journal of Morphology. v. 183, p. 87-115, 1985.

ORTENZI, A. V.; TARDELLI, M. A. Anestesiologia - SAESP. São Paulo: Atheneu, 1996. p. 358-371.

ROCHA, L. M. M. S. Estudo Anatomo-anestesiológico do Segmento Lombar ( $\mathrm{L}_{1}$ a $L_{6}$ ) em cães. 2003. $81 \mathrm{f}$. Dissertação (Mestrado em Anatomia dos Animais Domésticos e Silvestres). Faculdade de Medicina Veterinária e Zootecnia, Universidade de São Paulo, São Paulo, 2003.

SHIMIDT, G. V.; OECHTERING, O. Epidural anaesthesia in dogs and cats - still an alternative to general anaesthesia. Journal of Veterinary Anaesthesia, v. 20, n. 10, 1993.

SISSON, S.; GROSSMAN, J. D. Anatomia de los animals domesticos. 4. ed. Buenos Aires: Salvat, 1979. 952 p.

SKARDA. R. T. Local and regional anesthetic and analgesic techniques: dogs. In: THURMON J. C.; TRANQUILLI, W. J.; BENSON G. J. Veterinary Anesthesia. Pennsylvania: Williams \& Wilkins, 1996. p 16, 426-447.

SPINOSA, H. S.; GÓRNIAK S. L. Tranqüilizantes, relaxantes musculares de ação central e antidepressivos. In: Farmacologia aplicada à medicina veterinária. 3. ed. Rio de Janeiro: Guanabara Koogan, 2002, p. 146-157. 
SUSKO, I.; PERRONI, M.A.P.; TRANQUILIM M.V.; PERRONI, C.R.C.; OKAR, R.G.; DEMANTOVA C.A. Efeitos da cetamina-s em cães. In: CONGRESSO BRASILEIRO DE CIRÚRGIA E ANESTESIOLOGIA VETERINÁRIA, 4., 2000, Goiânia, Anais... Goiânia: CBCAV, 2000, p.189.

TORSKE, K. E., DYSON D. H. Epidural analgesia and anesthesia. The Veterinary Clinics of North America: Small Animal Practice, v.30, n. 4, p. 859-871, 2000.

WHITE, P. F.; HAM, J.; WAY, W. L.; TREVOR, A. J. Pharmacology of ketamine isomers: Studies in Surgical Patients. Anesthesiology, v. 52, p. 231-239, 1980.

WHITE, P.F.; SCHUTTLER, J.; SHAFER, A. Comparative pharmacology of the ketamine isomers: studies in volunteers. British Journal of Anaesthesia, v. 57, p. 197-203, 1985. 